\title{
PROPOSTAS ESTRATÉGICAS DE GESTÃO DE RISCOS PARA A NANOTECNOLOGIA
}

\author{
Marco Antonio Utrera Martines ${ }^{1}$ \\ Nivaldo dos Santos ${ }^{2}$ \\ Loreci Gottschalk Nolasco ${ }^{3}$
}

\begin{abstract}
Resumo
As pesquisas com o emprego da escala nano surgem como uma das mais espetaculares possibilidades da ciência no Século XXI, com habilidades de construir materiais, dispositivos e sistemas com precisão atômica, capazes de agir de uma forma fundamentalmente diferente em comparação com o seu respectivo material em escala macro. Apesar da disseminação de materiais e equipamentos contendo nanopartículas, os possíveis riscos e impactos na saúde pública e no ambiente não foram avaliados, somado ao fato da ausência, na quase totalidade dos países produtores, inclusive no Brasil, de regulamentação específica que estabeleça diretrizes de gestão e monitoramento da nanotecnologia durante todo o seu ciclo de vida. Pela análise bibliográfica, descrevemos alguns princípios e indicadores que devem ser adotados como medidas de supervisão e de gerenciamento preventivo dos riscos decorrentes do desenvolvimento nanotecnológico, a fim de garantir segurança jurídica aos envolvidos no processo e na produção da nanotecnologia, dentre os quais destacamos a abordagem precaucional e regulamentos específicos obrigatórios. Apontamos ainda algumas propostas estratégicas de gestão de riscos, incluindo controles no local de trabalho, programas voluntários e seguros. Concluímos que a gestão de riscos da nanotecnologia poderá ser feita em vários níveis, incluindo as agências reguladoras governamentais na definição de normas ambientais, de saúde e de segurança, as empresas na implementação de programas de manejo industrial de higiene e produtos e as seguradoras na formulação de políticas de cobertura e preços.
\end{abstract}

Palavras-chave: Nanotecnologia e Direito. Risco nanotecnológico. Indicadores para gestão de riscos.

\section{A NANOTECNOLOGIA: INVESTIMENTOS, DESENVOLVIMENTOS, APLICAÇÕES E DESAFIOS}

O intenso desenvolvimento nos mais diversos setores das relações sociais e humanas ao longo do século

\footnotetext{
${ }^{1}$ Doutor e Pós Doutor em Química Docente Departamento de Química da Universidade Federal de Mato Grosso do Sul. Docente do Programa de Pós-Graduação Doutorado em Biotecnologia e Biodiversidade.. E-mail. marco.martines@ufms.br ${ }^{2}$ Doutor e Pós-Doutor em Direito. Docente do Departamento de Direito - Extensão Goiás, da Universidade Federal de Goiás, da Pontifícia Universidade Católica de Goiás e do Programa de Pós Graduação, nível Doutorado da Rede Pró Centro Oeste de Pesquisa e Inovação em Biotecnologia e Biodiversidade, pela Universidade Federal de Goiás. Secretário Especial de Ciência e Tecnologia do Instituto Goiano de Direito Ambiental e Diretor de Desenvolvimento da Associação Goiana dos Advogados. Filiado a SBPC e ao CONPEDI. E-mail: nivaldodossantos@bol.com.br.

${ }^{3}$ Doutoranda da Rede Pro Centro Oeste de Pesquisa e Inovação, em Biotecnologia e Biodiversidade, pela Universidade Federal de Goiás. Docente do Curso de Direito da Universidade Estadual de Mato Grosso do Sul. E-mail: lorecign@gmail.br.
} vol.09, no. 04, Rio de Janeiro, 2016. pp. 2450-2488 
$\mathrm{XX}$, fez com que o mundo contemporâneo se distinguisse em muito, daquele vislumbrado anteriormente. Nos dias globalizados em que vivemos, é impossível negar a interconectividade dos mais diversos sistemas, sobretudo em virtude da expansão do capital, a evolução das telecomunicações e a multiplicação de novas tecnologias que acabam afetando diretamente todas as regiões do planeta.

A globalização fomenta as relações internacionais de tal modo que os países, cada vez mais, estão abrindo as suas fronteiras a "serviços de interesse inicialmente privados", os quais evoluíram e passaram a atuar concomitantemente com os Estados na sociedade internacional contemporânea, impondo também a sua necessidade de expansão (DELMAS-MARTY, 2003, p. 131). Nesse escopo é que observamos a busca por novas tecnologias e por avanços no campo da ciência, os quais inicialmente iriam melhorar a vida da população, garantindo a esse setor um maior capital - o que é essencial nessa etapa de mundialização.

Neste contexto de avanços tecnológicos, o desenvolvimento da nanotecnologia é considerado um novo capítulo na história mundial, uma vez que abre uma nova fronteira para os avanços nas mais diversas áreas do conhecimento, as quais podem auxiliar tanto para o avanço de técnicas já utilizadas, quanto para a produção de novos produtos - atendendo, assim, as necessidades pontuais do ser humano, principalmente na área da saúde (STOKES, 2009).

Ela é importante para os avanços tecnológicos, pois além de reproduzir aquilo que os "organismos naturais podem criar", ela pode ir além - o que possibilita a "criação de novos materiais com uma precisão extraordinária, em níveis atômicos" (PINSON, 2004, p. 279, 283). A capacidade de manipular o átomo abre muitas perspectivas. De fato observar a matéria e trabalhá-la à escala atômica constitui um horizonte fascinante de inovações prometedoras. O sonho é bem "refazer o que a vida fez, mas à nossa maneira", nos termos de JeanMarie Lehn (Prêmio Nobel de Química em 1987).

As nanopartículas têm diferentes propriedades físico-químicas em comparação com o seu respectivo material em escala macro, incluindo diferentes propriedades ópticas, comportamento térmico, resistência do material, solubilidade, condutividade e atividade catalítica (BURLESON et al.2004). Nessa escala, os materiais se comportam de forma inesperada, com propriedades que diferem, física, química e biologicamente de suas contrapartes maiores (LANONE et al.2006; FDA-Task Force, 2007) (graças à superfície e efeitos quânticos), em particular no âmbito de 10-20nm, por causa das propriedades tais como o domínio de efeitos quânticos, efeitos de confinamento, reconhecimento molecular e um aumento na área de superfície relativa (ROCO et al. 2012). Tais diferenças podem incluir alterações nas propriedades magnéticas, atividade elétrica ou óptica, aumento da integridade estrutural ou alteração da atividade química ou biológica.

A nanotecnologia já encontra ou deve encontrar aplicações em praticamente todos os setores industriais e de serviços. Há aplicações de grande escala como os nanocompósitos poliméricos, produzidos a partir de commodities como os termoplásticos e as argilas, ao lado de produtos fabricados em quantidades reduzidas, mas vol.09, no. 04, Rio de Janeiro, 2016.pp. 2450-2488 
com elevado valor agregado e criados para as tecnologias de informação e de telecomunicações.

A multiplicidade de aplicações é percebida ao examinar diferentes programas nacionais ou multinacionais de nanotecnologia, que revelam os diferentes modos de classificação dos temas, dos objetivos e das facilidades experimentais necessárias. Silva (2003) descreve que além do surgimento de novos computadores, se projeta o desenvolvimento de automóveis, componentes metálicos e não-metálicos, equipamentos para uso aéreo e espacial, instrumentos de proteção do meio ambiente, aplicações no campo da energia, da óptica e da ciência dos materiais. Também na medicina e na farmácia, o seu emprego já é amplamente favorável a avanços de todo tipo, além da produção de medicamentos potentes, de creme antirrugas, entre tantos outros produtos comerciais.

Dentre as contribuições imagináveis da nanotecnologia no campo da medicina, Ferronato (2010, p. 19) descreve "[...] o aumento da qualidade de vida e sua duração, através de nanossensores incorporados ao próprio organismo e que viajam pelo mesmo como se fossem vírus pelo sangue, onde poderão detectar doenças antes que se expandam". Também Schulz (2013) aduz que "associados às nanopartículas - um dos carros-chefe da nanotecnologia -, estão os sistemas de carregamento e liberação de drogas: remédios nanoparticulados encapados por um material que se associa seletivamente a células doentes, permitindo atingir apenas o alvo (a doença) com maior eficiência, necessitando, assim, de doses menores e diminuindo os efeitos colaterais".

Não se nega o potencial que a tecnologia pode proporcionar no desenvolvimento de nações (Estados)o que poderá gerar também benefícios diretos ao desenvolvimento da sociedade, incluindo o meio ambiente natural como um todo. Como vimos, verificam-se possibilidades de melhoramento nas propriedades de diversos produtos utilizados pelas pessoas, mas também seus resíduos devem atingir potencialmente o meio ambiente natural, sejam alimentos, pinturas, tecidos, embalagens “inteligentes", materiais esportivos, medicamentos.

$\mathrm{Na}$ medicina, as perspectivas são boas, especialmente em medicamentos que agem diretamente sobre a célula doente. $\mathrm{Na}$ nanomedicina, a utilidade de nanopartículas se deve pela interação diretamente com as biomoléculas, tanto da superfície da célula como dentro desta, contudo, embora haja avanços nesta área, constituindo seu núcleo, o uso de nanoestruturas e nanodispositivos para novos sistemas de prevenção, diagnóstico, tratamento e regeneração (EC, 2005), o potencial efeito (ou riscos) na saúde humana devido à exposição prolongada ainda não foi estabelecido. Da mesma forma, será preciso verificar possíveis consequências de riscos e danos ao meio ambiente.

Alguns analistas descrevem a nanotecnologia como uma espada de dois gumes. Por um lado, alguns dão conta, por exemplo, que as partículas em nanoescala podem entrar e acumular-se em órgãos vitais, tais como os pulmões e o cérebro, causando potenciais danos ou a morte de seres humanos e animais, e que a difusão de partículas nanoescala no ambiente pode prejudicar ecossistemas. Por outro lado, alguns analistas acreditam que a nanotecnologia tem o potencial de trazer benefícios importantes à saúde, segurança e ao meio ambiente vol.09, nº. 04, Rio de Janeiro, 2016. pp. 2450-2488 2452 
(exemplo, reduzindo o consumo de energia, a poluição e as emissões de gases com efeito de estufa; remediação de danos ambientais; cura, gerenciamento ou prevenção de doenças; e oferecendo novos materiais, mais fortes para proteção e reforço da segurança, com capacidade de autorreparação e adaptação) (SARGENT JR. 2013).

A Iniciativa Nacional em Nanotecnologia (do inglês, National Nanotechnology Initiative - NNI) dos Estados Unidos, em 2013 reconheceu que “[...] apesar de produtos entrarem no mercado global, ainda há dúvidas sobre os potenciais riscos e benefícios da nanotecnologia para os consumidores, trabalhadores e, mais genericamente, para a saúde humana e o meio ambiente". Com base em informações divulgadas pela Agência de Proteção Ambiental (do inglês, Environmental Protection Agency - EPA) dos Estados Unidos, existem sete tipos de nanomateriais (exemplo, dióxido de titânio em nanopartículas $\left(\mathrm{TiO}_{2}\right)$, óxido de zinco, ouro, carbono (negro de fumo: borracha e tintas), prata) utilizados para consumo e que podem ser efetivamente prejudiciais à saúde e ao meio ambiente, diante da possibilidade de persistência ou bioacumulação. Estes e outros nanomateriais são objeto de investigação pela EPA.

Como área científica emergente, os nanomateriais têm várias características inerentes (incerteza, falta de conhecimento e efeitos adversos potencialmente irreversíveis à saúde em longo prazo) que são susceptíveis de gerar preocupação, desconfiança ou medo (OSHA, 2012). Ademais, um alerta aponta para a necessidade urgente em se avaliar suas implicações sociais. De acordo com o grupo canadense Erosion, Technology and Concentration(ETC Group):

Enquanto a nanotecnologia oferece oportunidades para a sociedade, também pode trazer profundos riscos sociais e ambientais não apenas por ser uma tecnologia capacitadora de tecnologias para a indústria biotécnica, mas também porque ela envolve a manipulação atômica que poderá tornar possível a fusão do mundo biológico com o mecânico.

A partir daí, inúmeras questões jurídicas, éticas e morais são desenvolvidas, principalmente no que diz respeito à saúde humana e ao meio ambiente, pois pesquisas (e já centenas de produtos à disposição no mercado), que envolvem diretamente o ser humano (trabalhadores e consumidores) e o seu ecossistema são realizadas na tentativa de melhorar a qualidade de vida de pessoas, sem, contudo, avaliar os riscos e danos até irreversíveis que tais experimentos e, por conseguinte, seus processos, produtos e serviços, possam causar.

Somado a isso, no cenário jurídico atual, entre duas centenas de Estados e no Direito Internacional, não se tem notícia de normas estatais ou "interestatais" em vigor, relativas a qualquer forma de prevenção/precaução, informação e fiscalização específica sobre riscos que podem ser gerados a partir do desenvolvimento com nanotecnologia, com exceção de uma recente modificação do Código Ambiental Francês, a partir de 2013 e nos Estados Unidos, a alteração na norma relativa a materiais perigosos e gestão de resíduos, na cidade de Berkeley, Califórnia, em 2006, após ter adotado o princípio da precaução.

De um modo geral, portanto, não se tem uma diferenciação entre o tratamento legal da nanotecnologia em relação a outras tecnologias. Inexistem metodologias impostas pelas normas jurídicas para a correta avaliação 
de toxicidade, no curto, médio e longo prazos, para nanomateriais e dos possíveis efeitos da acumulação e combinação com outras substâncias nos ecossistemas e no corpo humano.

Da mesma forma, não está claro se as normas existentes relativas à proteção do meio ambiente e da saúde humana, são capazes de enfrentar as incertezas e os riscos da nanotecnologia. Ainda, não se tem como precisar em que medida adaptações nas normas existentes podem dar conta da complexidade das múltiplas aplicações dessa nova tecnologia iniciada no século XX, quando tudo era expectativa desenvolvida no início do século XXI, quando muito do que se projeta em termos de nanoinovação se torna realidade, ou se vislumbra para um horizonte próximo, embora o cenário de incertezas ainda persista (BERGER FILHO et al.2013).

Por conseguinte, Maynard (2005) aduz que os líderes da indústria, do governo, da pesquisa e outros setores devem agir conjuntamente para ter uma visão de longo prazo do que é conhecido e desconhecido e desenvolver metodologias de gerenciamento e de segurança sobre os potenciais desafios colocados pelas tecnologias emergentes, à saúde e ao meio ambiente.

Assim, o foco de atenção não são apenas as descobertas na escala nano, mas também as repercussões que essas pesquisas gerarão na natureza e os modos como elas atingirão a vida humana no ecossistema. Como se pode verificar, o problema não são as descobertas em si, mas os seus reflexos na vida das pessoas e na estrutura do planeta. Pesquisas já demonstraram que camundongos que receberam nanotubos de carbono desenvolveram lesões biológicas semelhantes àquelas provocadas por inalação de amianto. Recentemente, Andrade et al. (2013) analisaram 17 propostas de gestão de riscos com nanomateriais, concluindo que apesar de não convergirem para uma abordagem e consenso, "mas de maneira geral, todas fazem referência ao processo de identificação dos riscos, de avaliação da exposição, da definição dos riscos, passando à eliminação, substituição ou controle destes riscos através de medidas técnicas ou organizacionais".

No mesmo sentido, Riccardi et al. (2013) avaliaram que em alguns países, por exemplo, o Brasil, os instrumentos de regulação/fiscalização confrontam-se com os seguintes aspectos: "dificuldade para o escalonamento de processos; custo elevado de alguns nanomateriais; dificuldades nas etapas de controle de qualidade e gestão de riscos; e, preocupação de rejeição pública aos nanoprodutos. Desta forma, uma lentidão em iniciativas em nanorregulação foi observada analisando-se a literatura”. Após revisarem a legislação internacional em nanotecnologia, apontaram que todas as ações de segurança "visam apenas a precaução quanto à exposição ocupacional e minimização dos efeitos nocivos de descarte desses nanomateriais, levando em consideração a composição química desses compostos e apontando as mesmas medidas de segurança das substâncias químicas perigosas. Porém, não há indícios quantos aos reais efeitos do uso contínuo dos nanoprodutos à saúde humana”. Alertam que "as agências reguladoras brasileiras negligenciam o aspecto das propriedades específicas de nanopartículas no organismo", uma vez que os mecanismos reguladores atuais possibilitam, por exemplo, "que um nanoproduto seja disponibilizado no mercado sem um controle rigoroso por novos testes de toxicidade que vol.09, no. 04, Rio de Janeiro, 2016. pp. 2450-2488 2454 
delineariam com maior precisão os níveis aceitáveis dos nanocompostos no organismo e meio ambiente". Por último, os autores propõem "a criação de sistema regulatório específico para a nanotecnologia acoplado a um sistema de vigilância e fiscalização públicas".

\section{POTENCIALIDADES (BENEFÍCIOS E RISCOS) DA NANOTECNOLOGIA E A NECESSIDADE DE SUA REGULAMENTAÇÃO PELO DIREITO}

Rejeski et al. (2008) apontam que a nanotecnologia pode ser a próxima revolução industrial, com a esperança de que suas inovações permitam direcionar a nossa sociedade em um caminho mais sustentável. Para eles, à medida que explorarmos essa nova fronteira tecnológica, teremos duas opções fundamentais: (a) garantir a segurança dos materiais e produtos em todo o seu ciclo de vida nanoprojetados, associado a também capitalizar/aproveitar os benefícios ambientais, sociais e econômicos dessa tecnologia; ou (b) produzir nanomateriais e produtos de forma extremamente rápida e sem a suficente consideração e prevenção dos potenciais efeitos adversos. E concluem: "as experiências do passado com a introdução de novas tecnologias e materiais (ex., amianto, chumbo, alimentos geneticamente modificados, DDT) deve convencer o governo e a indústria que muito pode dar errado se descaracterizarmos a bússola social ou científica, nesta fase inicial da nossa jornada".

A aplicabilidade da nanotecnologia oferece a perspectiva de grandes avanços científicos para melhorar a qualidade de vida e como qualquer área da tecnologia que faz uso intensivo de novos materiais e substâncias pode trazer algum risco ao meio ambiente e à saúde humana ou animal. Por isso, a avaliação do potencial impacto biológico dos nanomateriais se tornou de grande importância nos últimos anos, uma vez que o rápido ritmo de desenvolvimento da nanotecnologia não foi acompanhado por uma investigação completa de sua segurança. As mesmas propriedades que tornam as nanopartículas interessantes para aplicações, como seu pequeno tamanho, sua enorme superfície e sua alta reatividade, também as tornam acessíveis a locais anteriormente inacessíveis em sistemas vivos, com consequências potencialmente significativas para o ambiente. Contudo, a regulamentação jurídica do uso de nanomateriais avançou lentamente no sentido de garantir a segurança dos ecossistemas em contato com nanomateriais (COHEN et al.2013).

Como face oposta da nanotecnologia, há vários efeitos ambientalmente nocivos causáveis pelo seu uso desregulado. As características das nanopartículas e as consequências do seu comportamento quando dispersas no ambiente fazem com que suas propriedades físicas e químicas sejam totalmente diversas das partículas das mesmas substâncias em maior escala (MAYNARD, 2005). Seu diminuto tamanho e a decorrente elevada energia superficial fariam com que, ao serem dispersas no ambiente, reagissem de modo ainda imprevisível. A contaminação do organismo humano por nanopartículas também poderia resultar em várias reações complexas e 
interações biológicas, físicas e químicas, que poderão desencadear processos de defesa celular desconhecidos, a depender do tipo e da natureza da nanopartícula, bem como das células ou dos tecidos atingidos e seus mecanismos de defesa (EPA, 2007).

Viegas et al. (2010) baseados em estudos divulgados pela companhia de seguros e resseguros Swiss Reinsurance Company (2004) informam que quando as nanopartículas transpõem a barreira de tais órgãos de acesso ou quando são inseridas deliberadamente na corrente sanguínea (medicamentos e contrastes), uma nova série de questionamentos emerge. Partículas estranhas, quando presentes no sistema circulatório, são absorvidas por fagócitos especializados e são expulsas do organismo. Entretanto, tal regra não se aplica aos nanomateriais. Nanopartículas de tamanho inferior a 200nm não são absorvidas por fagócitos, mas, surpreendentemente, por células que sequer desempenham a função de defesa. Uma vez absorvidas por tais células (glóbulos vermelhos, e.g.), podem transitar pelo organismo de maneira livre e irrestrita. Coração, medula, ovários, fígado, músculos, e até mesmo o cérebro - o mais protegido órgão do corpo humano - são penetrados, sem maiores dificuldades, por nanopartículas presentes no sangue.

No mesmo sentido, Grimaldi et al. (2007):

Las posibilidades de interacción podrín traducirse, entre otros efectos, en un incremento del estrés oxidativo, la inflamación, el daño mitocondrial, la captación por parte del sistema reticuloendotelial y en perturbación de la función fagocítica, degradación proteica, disfunción endotelial, generación de neoantígenos, alteración del ciclo celular y daño del ácido desoxirribonucleico (ADN). Estudios en seres humanos y en animales sugieren que la inhalación de nanopartículas y su translocación a la sangre se han relacionado con eventos coronarios y arritmias. Se desconocen los alcances de la perturbación del sistema inmune. La interacción con nanopartículas de las proteínas de las células hepáticas, del bazo y de los ganglios linfáticos puede cambiarles la antigenicidad y generar respuestas autoinmunes.

Estudos atestam que os riscos potenciais para a saúde humana são consideráveis, não apenas como resultado das nanoestruturas de exposição lançadas no meio ambiente e que se deslocam ao longo da cadeia alimentar, mas também devido à sua utilização em nanomedicina. Isso é plenamente reconhecido pela Plataforma Tecnológica Europeia (ETP) sobre Nanomedicina desenvolvida por representantes da indústria (ex., Bayer, Novartis, Schering, GlaxoSmithKline) ${ }^{4}$ quando notaram que:

The risks and challenges of NanoMedicine comprise issues of toxicity and carcinogenicity, as well as long-term stability and excretion pathways for artificial nanostructures, and technological challenges in molecular manufacturing, quality assurance and eventually, the programmability of nanodevices (EC, 2005).

Embora tenha aumentado bastante os estudos sobre nanotoxicologia nos últimos anos, esta linha de pesquisa ainda está em sua infância. Enquanto a toxicidade de certos nanomateriais, mais notavelmente os nanotubos de carbono, nanopartículas de prata, e nanopartículas de dióxido de titânio, estejam bem documentados, a toxicidade dos outros é em grande parte desconhecida (WIJNHOVEN, 2009). Há ainda uma

\footnotetext{
${ }^{4}$ São apontadas além das mencionadas: bioMérieux, UCB, Philips Medical Systems, Siemens AG, Neuropharma, ION-TOF GMBH, Genomita, Gambro, Selex Sensors and Airborne Systems, entre outras.
} 
grande quantidade de incerteza e conhecimento inconclusivo sobre a caracterização de nanomateriais; há ainda controvérsias quanto à definição aceita, que se referem principalmente à sua complexidade científica intrínseca. Há problemas com a extrapolação dos métodos de avaliação de risco tradicionais para os nanomateriais, e estes limitam a capacidade de calcular ou fazer previsões quantitativas em relação a riscos potenciais (SCENIHR, 2007; WIJNHOVEN, 2009).

Razão disso, as avaliações da Iniciativa Nacional em Nanotecnologia (do inglês, National Nanotechnology Initiative - NNI) dos Estados Unidos, elaboradas pelo Escritório Executivo do Conselho de Assessores do Presidente em Ciência e Tecnologia (PCAST, 2010, 2012 e 2014) sublinharam preocupações de riscos à saúde e à segurança dos nanomateriais: "a investigação até à data sugere que alguns produtos da nanotecnologia têm o potencial de apresentar riscos novos ou incomuns para a saúde humana e o meio ambiente", expressando a necessidade de integração entre a investigação da nanotecnologia relacionada com segurança, saúde e meio ambiente e o tipo de formulação de política de informação para efetivamente gerenciar os potenciais riscos dos nanomateriais, "a fim de melhorar a tomada de decisão quanto à regulamentação e a comercialização da nanotecnologia com a aceitação, a confiança e o apoio do público". Do mesmo modo, em 2014, o Conselho Nacional de Pesquisas (do inglês, National Research Council - NRC) dos Estados Unidos, concluiu que "a caracterização dos riscos de nanomateriais artificiais em todo seu ciclo de vida é um desafio científico que exige abordagens científicas, quantitativas e sistemas integrados".

O campo de rápido crescimento da nanotecnologia e seus produtos coloca novos e importantes desafios para os tomadores de decisões políticas e instituições ambientais. Em certo sentido, esses desafios, que incluem questões como as limitações dos dados e incertezas sobre muitos efeitos sanitários e ambientais, são típicos daqueles de gerações anteriores de gestão de produtos químicos.

Diante do desafio representado pelas novas tecnologias, em especial a nanotecnologia, em que bom e mau estão intimamente conectados, Fukuyama (2003, p. 190) defende que "os países devem regular politicamente o desenvolvimento e o uso da tecnologia, criando instituições que discriminem entre aqueles avanços tecnológicos que promovem o florescimento humano e aqueles que representam uma ameaça à dignidade e ao bem-estar humanos." É importante que haja regulamentação não para limitar o estudo e cercear o desenvolvimento tecnológico, mas para garantir que essa tecnologia seja utilizada em prol do ser humano, visto ser essa a sua finalidade (ENGELMANN et al.2014). O grande problema é exatamente estipular quais são os riscos que a nanotecnologia apresenta à saúde humana e ao meio ambiente, visto que ela ainda é muito incerta, em virtude da falta de pesquisas específicas (STOKES, 2009).

Há ainda uma grande discussão a respeito da regulamentação destes materiais por ser uma área nova do conhecimento. Além disso, há discussão entre os nanotoxicologistas sobre a métrica apropriada para avaliação da toxicidade de nanopartículas (JESUS et al. 2014). Para os governos, a complexidade da ciência, o ritmo acelerado vol.09, nº. 04, Rio de Janeiro, 2016.pp. 2450-2488 2457 
de mudança científica, a natureza incerta de risco para o desenvolvimento de tecnologias, bem como a diversidade da comunidade, apresenta enormes desafios para uma regulamentação efetiva (BENNETT, 2008; BROWNSWORD, 2008). Atualmente, a inovação em aplicações com nanotecnologia está à frente da política reguladora, levantando preocupações de que questões éticas, econômicas, jurídicas, sociais, toxicológicas e ambientais estão atrasadas ou defasadas (MCCOMAS et al.2011).

Organizações internacionais e cientistas informam que a avaliação do risco é complicada pelo enorme número de variações dos nanomateriais em desenvolvimento, bem como as diversas formas em que serão utilizados (EPA, 2007). Até mesmo dentro de uma determinada classe de nanomateriais, existe uma grande variedade de formas, tamanhos e outras caracterizações que podem afetar a toxicidade, criando uma necessidade urgente para ensaios de toxicidade relativamente rápidos e de baixo custo ou modelos para prever os riscos da nanotecnologia de diferentes produtos (CLARK, 2011).

Da mesma forma, o Comitê Científico em Emergentes e Recentemente Identificado Riscos à Saúde (do inglês, Scientific Committee on Emerging and Newly Identified Health Risks - SCENIHR) (2007) da Comissão Europeia, observou que "especialistas são de opinião unânime de que os efeitos adversos das nanopartículas não podem ser previstos (ou derivados) da toxicidade conhecida de material de tamanho macroscópico, que obedecem às leis da física clássica”. Nessa direção, a Real Sociedade e Real Academia de Engenharia do Reino Unido (do inglês, United Kingdom's Royal Society and Royal Academy of Engineering) (2005) enfatizaram que "partículas livres na faixa de tamanho nanométrico levantam preocupações ambientais, de saúde e de segurança e sua toxicologia não pode ser inferida a partir de partículas do mesmo produto químico em um tamanho maior".

Tran (2005) afirma que "devido ao tamanho e as formas que são usadas, as nanopartículas têm propriedades físico-químicas específicas, se comportando de forma diferente de seus materiais de origem”, e que quando liberados, interagem também de forma diferente com os sistemas vivos. Nesse caso, "não seria possível inferir a segurança dos nanomateriais, utilizando a informação derivada do material de origem a granel”. No mesmo sentido, em 2010, o Projeto sobre Nanotecnologias Emergentes (do inglês, Project on Emerging Nanotechnologies - PEN) reconhece que a nanotecnologia é representante de uma nova geração de questões ambientais, cujas consequências são difíceis de prever, em rápida evolução, dependente de mudança de tecnologia e inovações e, não costumam ser passíveis de soluções regulamentares e estratégias de aferição da toxicidade convencionais.

Enquanto o alcance e a escala dos desafios regulatórios não podem ser previstos, dada a incerteza e rápida mudança no desenvolvimento da tecnologia, o que é certo é que a regulamentação dessa tecnologia enfrenta complexidades e dificuldades sem precedentes, e que a governança global da nanotecnologia usando somente instrumentos tradicionais (não específicos) de regulação é inviável agora e pouco provável no futuro previsível (MARCHANT et al.2012a). 
Inobstante as discussões e debates, a questão da regulamentação da nanotecnologia ainda não resta definida em muitos países, inclusive no Brasil, o que não tem impedido que um grande número de produtos já esteja no mercado (PEN, 2013). Tal situação gera inquietação e desconforto em vários seguimentos da sociedade (governos, cientistas, Organizações não governamentais, indústria etc.) (ABDI, 2011, p. 29).

Especificamente em relação à biotecnologia, e agora a nanotecnologia - constata-se que a tensão entre a liberdade de atuação científica e a vinculação das suas consequências ainda permanece, diante do Direito, como realidade resistente à regulamentação. No que diz respeito, especificamente, à área das ciências biológicas, a primeira questão relaciona-se à competência dos poderes constituídos (em especial do Legislativo) "para legislar sobre un terreno tan especializado, campo donde los progresos se realizan, no de año en año ni de mes en mes, sino incluso de semana en semana" (FERNÁNDES, 1995, p. 39). Por isso, especialistas assinalam que o aumento de novas tecnologias (engenharia genética, biotecnologia, nanotecnologia) que, por razões de mercado faz crescer em ritmo vertiginoso o conhecimento nessa seara, faz também surgir questões inteiramente novas para as quais é impossível resposta na mesma velocidade, inclusive da Ciência Jurídica (LIMANETO, 1997).

O prodigioso avanço da ciência, como alerta Castro (2010), particularmente no setor da biologia, engenharia genética, química, medicina, biotecnologia, e, agora da nanotecnologia, "impôs e continua a impor ao legislador nas últimas décadas a crescente vigilância quanto à possibilidade de riscos e danos perpetráveis à integridade física e mental dos seres humanos, a fim de que o progresso científico nesse importante e inesgotável campo de investigação se compatibilize com as normas e princípios tutelares da personalidade humana”.

Tem-se nesse passo, que o progresso técnico-científico, assim como pela utilização comercial de seus resultados é uma fonte principal de atuação ativa do Estado de Direito na elaboração de leis, as quais, geralmente "consistirá de restrições a algumas liberdades em particular ou em liberdades de indivíduos em particular ou, ainda, da imposição de determinadas obrigatoriedades de cautela”. E já que isso atua como intervenção nos direitos fundamentais dos envolvidos, Grimm (2006, p. 140-1) aduz: "faz-se necessária, por sua vez, a existência de leis para tanto"; citando como exemplo mais novo para tanto a decodificação completa do genoma humano, anunciada como diretamente iminente. "Já que tanto choques quanto relações de força são distribuídos de forma desigual, a conciliação de interesse não surge mediada pelo mercado, mas só pode ser produzida por uma instância que esteja obrigada com ambos os interesses e os equilibre segundo pontos orientadores ao bem comum" (direitos fundamentais).

O Direito, diante desse salto no futuro por parte da medicina e da biogenética, deve oferecer os serviços da normatividade e da pacificação social pela via da legalidade (CASTRO, 2010). Legalidade pautada na Constituição de 1988. Esta fundada sob o paradigma do Estado Democrático Constitucional de Direito, de viés garantista, compromissório e dirigente, que atravessa vertical e horizontalmente as relações sociais é "a representação de um contrato social, diga-se de passagem, de um contrato que encerra no seu interior, valores vol.09, n. 04, Rio de Janeiro, 2016. pp. 2450-2488 2459 
históricos em contínua referência ao momento de sua formação" (STRECK, 2008, p. 91), e, ainda, é o resultado de um constituir social, representação das aspirações maiores de um povo, de conteúdo normativo substancial, de acentuada carga axiológica, dirigente para o campo da formulação, interpretação e aplicação das leis (viés de Canotilho). Uma vez que o objeto da Constituição são as condutas humanas possíveis e que tenham algum interesse para os seres humanos, tornando-as protegidas por uma instituição criada pelos mesmos - o Estado.

Pautamos que o modelo de Estado Democrático de Direito Constitucional desenhado na CF/88, seja capaz de fornecer instrumentos jurídicos aptos a lidar com os desafios gerados a partir da sociedade de risco (crise ambiental contemporânea) e para tanto, partimos do pressuposto de que a Constituição de 1988 adotou um modelo avançado, pois erigiu o meio ambiente à categoria de direito fundamental, estendendo às futuras gerações a prerrogativa de usufruí-lo em iguais condições, além de estabelecer uma sessão (arts. 196 a 200) voltada à garantia e defesa do direito fundamental à saúde. Em especial descrevemos o art. 196. "A saúde é direito de todos e dever do Estado, garantido mediante políticas sociais e econômicas que visem à redução do risco de doença e de outros agravos e ao acesso universal e igualitário às ações e serviços para sua promoção, proteção e recuperação".

A partir desses desafios, a seguir são apresentados alguns princípios e indicadores para monitoramento e gerenciamento de riscos, bem como propostas inovadoras e ideias de governança e supervisão com nanotecnologia.

\section{PRINCIPIOS E INDICADORES PARA GERENCIAR OS RISCOS NANOTECNOLÓGICOS}

Entre os princípios e indicadores que devem ser seguidos para a supervisão da nanotecnologia e nanomateriais, cita-se, a abordagem precaucional, regulamentos específicos obrigatórios, preocupação com saúde e segurança dos trabalhadores, preocupação com a sustentabilidade ambiental, transparência, participação pública, estudos mais amplos acerca de impactos e responsabilidade do fabricante (NANOACTION, 2007).

Como analisamos no tópico anterior, a regulamentação jurídica estatal do uso, da pesquisa, do desenvolvimento e da inovação em nanotecnologia "passou para o topo da agenda tanto dos governos como da comunidade científica e tecnológica, uma vez que a insegurança jurídica é um dos principais fatores de represamento dos investimentos em novas tecnologias" (Hankin et al. 2014). Por isso observam Porter et al. (1999, p. 371-2): o sistema regulatório pode beneficiar e estimular quem promova "investigação e inovação responsáveis", como uma forma de "vantagem competitiva".

Quanto aos mecanismos de proteção ao meio ambiente e ao direito das futuras gerações, as novas tecnologias exigem que o Direito se molde à realidade, e seja capaz de fornecer respostas na medida em que as demandas jurídicas surgirem. Em relação às respostas que o Direito ainda não tem para a questão da 
nanotecnologia, podemos mencionar que quando ausente uma base científica sólida, se exige do Direito, decisões juridicamente vinculativas em condições de grande incerteza, ou seja, decisões de sim ou não sobre atividades, produtos, substâncias ou técnicas, de modo que os juristas devem agir com prudência e um especial bom-senso na aplicação das medidas evitatórias (ARAGÃO, 2008, p. 35).

Nesse aspecto, vale destacar o que estabelece a Declaração de Wingspread The Johnson Foundation (Racine, Wisconsin), sobre medidas de precaução para a nanotecnologia: "Quando uma atividade representa ameaças de danos ao meio ambiente ou à saúde humana, medidas de precaução devem ser tomadas, mesmo se algumas relações de causa e efeito não forem plenamente estabelecidas cientificamente" (LICO JÚNIOR, 2014).

Na prática, a aplicação do princípio da precaução pode dar-se através: a) da exigência da utilização de melhor tecnologia disponível para minimizar o risco de dano; b) da imposição do controle e monitoramento dos riscos; c) da exigência da disponibilização de mais informações sobre os riscos e o impacto ambiental de produto ou processo, d) da proibição da comercialização ou da liberação no meio ambiente de determinada substância ou produto, com base na gravidade e na irreversibilidade dos possíveis danos (ROCHA, 2008, p. 202).

Esse novo paradigma emerge da constatação de que a evolução científica traz consigo riscos imprevisíveis, os quais estão a exigir uma reformulação das práticas e procedimentos tradicionalmente adotados nesse campo. Isso porque, como registra Derani (1997) é preciso "considerar não só o risco de determinada atividade, como também os riscos futuros decorrentes de empreendimentos humanos, os quais nossa compreensão e o atual estágio de desenvolvimento da ciência jamais conseguem captar em toda densidade”.

Com isso, entendemos que o princípio da precaução deve ser aplicado ao gerenciamento dos possíveis riscos ocasionados pelo desenvolvimento da nanotecnologia, pois que reconhecido no direito interno e em documentos internacionais ratificados pelo Brasil, quando incertezas científicas em razão da alta complexidade da ciência e da sociedade se impõem, mormente no presente século XXI, além de ser um princípio importante para inverter a lógica atual, que segundo Beck (1999) não obedece à progressão, primeiro, a análise de riscos em laboratório e depois aplicação. Os testes, em geral, vêm após a aplicação e a produção precede a pesquisa dos riscos.

Como sumariado por Aragão (2006, p. 81), mesmo que os riscos com a utilização da nanotecnologia ainda sejam desconhecidos pela ciência, não se pode ficar "à espera de provas irrefutáveis e do consenso científico geral em torno delas", pois um dos objetivos do princípio da precaução é regular os riscos globais, retardados e irreversíveis, dos quais a nanotecnologia é apta a abranger. Em outro texto a autora alertou que em caso da projeção do risco de danos graves ou irreversíveis "na gestão antecipatória dos 'novos riscos' não podemos 'darnos ao luxo de esperar e verificar que estamos errados'. Os riscos são importantes demais e as consequências graves demais para ficarmos à espera das provas irrefutáveis e do consenso científico geral, em torno delas" (ARAGÃO, 2008, p. 24). 
Não apenas o princípio da precaução deve ser invocado e servir de base na tomada de decisões, mas também o princípio da informação deve ser mencionado e efetivamente aplicado. É preciso que as informações decorrentes do estudo dos riscos tenham ampla divulgação e estejam disponíveis para a sociedade, para que os atores envolvidos diretamente nas decisões sobre a limitação da nanotecnologia e a sociedade civil tenham melhores condições frente aos desafios surgidos com essa tecnologia.

Como Quina (2004) apontou, há "perspectivas animadoras dos benefícios da nanotecnologia para a melhoria do meio ambiente", contudo, alerta para que a comunidade em geral não subestime o potencial para danos ao meio ambiente, e como visto acima, à saúde humana. Referindo-se ao documento: Nanociências e Nanotecnologias: Oportunidades e incertezas, de julho de 2004 da Academia Real de Engenharia e da Sociedade Real do Reino Unido, Quina aponta que o estudo recomenda, entre outras coisas, "cuidado na manipulação ou aplicação de nanopartículas artificiais em forma livre (e.g., em processos voltados para a remediação do meio ambiente) e o tratamento de nanopartículas e nanotubos como substâncias químicas novas para fins regulatórios. Refere-se ainda à necessidade de pesquisa interdisciplinar voltada para as questões de toxicidade, epidemiologia, persistência e bioacumulação de nanopartículas".

Diante disto, tendo em vista a amplitude dos reflexos da revolução nanotecnológica nos mais diferentes campos da sociedade, torna-se imperioso que o Direito, como ciência, também se preocupe com os diferentes aspectos desta revolução, possibilitando a criação de instrumentos jurídicos com objetivo de efetivar medidas de gerenciamento preventivo do risco, baseado nos princípios da precaução, responsabilização civil prospectiva, informação e sustentabilidade, objetivando sempre o cuidado com o ser humano e o meio ambiente.

Isto porque entendemos que três são os bens jurídicos expressamente tutelados no que se refere à nanotecnologia: a vida, a saúde e o meio ambiente natural. Todos com supedâneo na Constituição Federal de 1988 e com perspectiva intergeracional. Tomemos como exemplo, a proteção ambiental (não um sentido setorial, adstrito ao universo ambiental, mas de teor geral e generalizante basilar na relação intergeracional do tecido social), estabelecido para as presentes e futuras gerações no art. 225 , caput, numa relação intratemporal e intertemporal, fundamentando, dessa forma, a aplicação do princípio da precaução voltada para uma amplitude temporal (prospectiva), até então desconsiderada pelo Direito, abarcando os direitos das gerações futuras vinculadas aos deveres da geração presente.

Essa nova arquitetura dos valores do Direito pode ser observada no princípio da "equidade intergeracional" (com suas bases no Direito Internacional) defendido por Weiss (1985; 1999), que abarca o princípio da solidariedade entre gerações ou da responsabilidade de longa duração, impositiva da equidade entre pessoas vivas no presente e pessoas que nascerão no futuro, como pilar do desenvolvimento sustentável (reconhecido como princípio da Ordem Econômica na CF/88, art. 170, VI, e do Direito Ambiental). Permitindose, com isso, a construção da teoria da responsabilidade civil prospectiva a qual reside no art. $1^{\circ}$, III, da CF/88, que vol.09, no. 04, Rio de Janeiro, 2016. pp. 2450-2488 2462 
trata da dignidade da pessoa humana.

Nesse aspecto, para a década 2010-2020, Roco et al. (2010), propõem que a pesquisa e o desenvolvimento em nanotecnologia mude seu foco para a governança pautada pelas necessidades sócioeconômica, com consequências significativas para a ciência, o investimento e as políticas regulatórias. Para isso propõem que será imperativo para essa década concentrar-se em quatro aspectos distintos do desenvolvimento da nanotecnologia: a) como a ciência e a engenharia em nanoescala podem melhorar a compreensão da natureza, proteger a vida, gerar descobertas inovadoras e de inovação, importa prever o comportamento, e construir materiais e sistemas de projeto em nanoescala - "progresso do conhecimento"; b) como a nanotecnologia pode gerar valor econômico e médico - "progresso material"; c) como a nanotecnologia pode promover a segurança, o desenvolvimento sustentável e a colaboração internacional - "progresso global”; d) como a governança responsável da nanotecnologia pode melhorar a qualidade de vida e a igualdade social - "progresso moral".

Nessa perspectiva, Linkov et al. (2009) asseveram que os aspectos científicos e da pesquisa são essenciais, pois desvelam o conhecimento técnico para avaliação dos riscos e dos impactos da nanotecnologia ao meio ambiente e à saúde humana, mas a gestão dos riscos exigirá a atuação de políticas públicas, do engajamento das partes envolvidas, da liderança governamental e de instrumentos reguladores. Esse último engloba desde o regulamento de melhores práticas a instrumentos de responsabilização.

Nesse contexto, torna-se possível afirmar que o Direito passa a ter um papel essencial no combate ao risco de danos nanotecnológicos, uma vez que o planejamento jurídico pode contribuir para a produção sustentável dessa tecnologia. Isso significa contribuir para o desenvolvimento sustentável, aqui entendido como "a política que busca estabelecer um ponto optimum de equilíbrio entre o crescimento econômico e a compatibilização com a proteção dos recursos naturais e o ambiente sadio, considerada obviamente a presença do Homem" (CARVALHO, 2003, p. 71).

O desafio para o Direito é estabelecer como a sociedade poderá colher os beneficios da produção e, concomitantemente não sofrer os danos associados com a saúde humana e riscos ambientais que podem advir da nanotecnologia. Ainda não há conhecimento disponível para definir todos os possíveis riscos associados aos nanomateriais, e assim, se torna necessária e imprescindível a gestão dos riscos de modo transdisciplinar com decisões que objetivem erradicar ou pelo menos reduzir os efeitos dos novos riscos.

É imperativo, portanto, que os governos, inclusive do Brasil, em conjunto com fabricantes (a indústria), laboratórios, cientistas e universidades, seguradoras e a comunidade jurídica, em ação conjunta na tomada de ações proativas, adote medidas na identificação e quantificação dos riscos da nanotecnologia, bem como na efetivação de legislação de biossegurança e do adequado descarte dos nanowastes (resíduos nanotecnológicos).

Pellin et al. (2016) relatam que há, ao redor do mundo, iniciativas organizadas que vem se antecipando na divulgação de informações como precaução aos possíveis infortúnios nanotecnológicos, divulgando vol.09, nº. 04, Rio de Janeiro, 2016. pp. 2450-2488 2463 
informações ao consumidor, sobre os produtos e serviços manufaturados com nanopartículas. O Danish Consumer Council e o Danish Ecological Council em cooperação com o Departamento do Meio Ambiente da Technical University Denmark (DTU) em 30 de janeiro de 2013 lançaram o sítio databasenano (www.nano.taenk.dk). O banco de dados catalogou mais de 1.200 itens elaborados com base nanotecnológica para consulta direta pelo consumidor, incluindo cosméticos, suplementos alimentares e outros itens.

Para os autores, iniciativa igual está sendo tomada no Brasil, sob a coordenação de Lenz e Silva, da Universidade de São Paulo, ao criar em março de 2015 o site HSEnano - Health, Safety, Enviroment (www.hsenano.com) com grande repositório informacional e de pesquisa a respeito do que vem sendo desenvolvido pela cadeira da engenharia de materiais em nanotecnologia e nanotoxicologia da universidade, com apoio nacional do Governo Federal e de parcerias internacionais.

No mesmo sentido, a Agência Brasileira de Desenvolvimento Industrial (ABDI, 2010, p. 42) produziu o documento "Panorama Nanotecnologia" objetivando informar os agentes econômicos sobre o pouco conhecimento dos impactos nocivos e riscos potenciais à saúde humana e animal e ao meio ambiente, além de alertar sobre a importância da elaboração de marcos regulatórios, bem como da tomada de conduta ética na exploração da atividade com nanotecnologia.

\section{PROPOSTAS ESTRATÉGICAS DE GESTÃO DE RISCOS PARA A NANOTECNOLOGIA}

O principal objetivo da gestão de risco é o de maximizar os benefícios de uma tecnologia, produto ou atividade ao mesmo tempo, buscar identificar, avaliar e controlar os riscos associados a essa tecnologia, produto ou atividade. A gestão de riscos pode ser feita em vários níveis, inclusive por agências reguladoras na definição de normas ambientais, de saúde e de segurança, por empresas na implementação de programas de manejo industrial de higiene e produtos e pelas seguradoras na formulação de políticas de cobertura e preços.

Enquanto essas propostas tiveram pouco impacto sobre a ação formal do governo, talvez o elemento mais comum e eficaz seja o reconhecimento de que o desenvolvimento seguro da nanotecnologia não pode depender exclusivamente de regulamentação ditada de cima para baixo pelo governo, mas sim exige participação ativa e responsável na gestão do risco por múltiplos e variados participantes. Especificamente, a implementação de práticas responsáveis de gestão de risco pelos reguladores, organizações não-governamentais, cientistas, seguradoras e talvez o mais importante de tudo, as empresas em todas as fases do ciclo de vida da nanotecnologia, será fundamental para preencher a lacuna de governança e garantir a segurança da pesquisa, desenvolvimento, fabricação, distribuição, utilização e eliminação dos produtos da nanotecnologia (ABBOTT, 2008; BOWMAN et al. 2008). O gerenciamento pró-ativo do risco pode impedir os tipos de reação adversa dos consumidores e 
controvérsias que têm limitado outras tecnologias, como a energia nuclear e os alimentos geneticamente modificados (BALBUS, 2007).

A partir do estudo de Marchant et al. (2012b), adaptamos algumas abordagens e ferramentas potencialmente relevantes de gestão de riscos para a nanotecnologia, incluindo controles no local de trabalho, programas e iniciativas de natureza voluntária (soft law), seguros e o princípio da precaução.

\section{Controles no local de trabalho}

$\mathrm{Na}$ ausência de regras formais e avaliações de risco quantitativas para os nanomateriais, há medidas em vigor que as empresas podem tomar para reduzir de forma prudente os riscos para os trabalhadores, que são susceptíveis de ser o grupo em maior risco de exposição à nanotecnologia (PCAST, 2005). De acordo com um relatório publicado pela Organização Internacional do Trabalho, em 2010, sobre os "riscos emergentes e novos padrões de prevenção em um mundo do trabalho em mutação", cerca de $20 \%$ das mercadorias produzidas em todo o mundo serão em certa medida, baseadas em nanotecnologia. Roco et al. (2010) relatam que o desenvolvimento com nanotecnologia na década 2010-2020 evoluirá para uma tecnologia de uso geral em 2020 com considerável impacto econômico, superando a previsão mundial para 2015 de US 1,5 trilhão para US $\$ 3$ trilhões até 2020, em produtos finais que incorporarão a nanotecnologia, com seis milhões de de trabalhadores empregados na fabricação e manuseio de nanopartículas. Isso resulta na necessidade de regras claras para a utilização e aplicação segura da nanotecnologia. Os nanomateriais têm estado atualmente sob investigações sobre riscos e avaliação do benefício em muitos grupos de pesquisa devido aos seus efeitos específicos resultantes da forma, morfologia, tamanho, incluindo a área de superfície, funcionalização, estrutura atômica e química de partícula.

Pesquisas apontam que, entre os trabalhadores da indústria foram encontradas evidências de mortalidade relacionada com a exposição de doença pulmonar (GILBERT, 2009; SONG et al. 2009). Essas observações, enquanto recorrentes, tem provocado considerável ansiedade e discussões sobre a resposta global da regulamentação. Pesquisas da indústria sugerem que a maioria das empresas que lidam com nanomateriais não realizam avaliações de risco ou de práticas sistemáticas de gestão de risco, em parte significativa, devido à falta de uma estrutura industrial geral para avaliar e gerir os riscos de nanomateriais (BALAS, 2010; HELLAND, 2008). No entanto, não são estabelecidas técnicas de higiene ocupacional para avaliar e gerenciar as exposições no local de trabalho. Essas ações consistem principalmente em reduzir as exposições aos trabalhadores. Até que mais informações estejam disponíveis sobre os riscos dos nanomateriais específicos, o plano de ação prudente para as empresas é minimizar a exposição do trabalhador por meio de controles de engenharia, melhores práticas no local de trabalho e equipamento de proteção individual (YOKEL et al.2011). 
Uma abordagem mais sofisticada que começa a diferenciar entre nanomateriais é a técnica de "controle de bandas", desenvolvida na indústria farmacêutica aos materiais e exposições do grupo, com base em indicadores qualitativos de perigo, de medidas adequadas de redução do risco (MURASHOV et al. 2009). As organizações dos Estados Unidos, Administração de Segurança e Saúde Ocupacional (do inglês, Occupational Safety \& Health Administration - OSHA) (2012) e o Instituto Nacional para a Segurança e Saúde Ocupacional dos Estados Unidos (do inglês, National Institute for Occupational Safety and Health - NIOSH) (2013), já estariam desenvolvendo materiais de orientação para as empresas implementarem uma abordagem de controle de bandas para os nanomateriais no ambiente de trabalho (Hellman, 2011). Murashov et al. (2009) informam que será preciso desenvolver métodos para identificar e avaliar sistematicamente materiais e processos alternativos mais seguros, citando que o NIOSH criou o Prevention through Design (PtD) como exemplo de abordagem precaucional, procurando antecipar os riscos potenciais de produtos e processos, envolvendo os trabalhadores nas instalações, métodos de trabalho e operações, processos, equipamentos, ferramentas, produtos, novas tecnologias e a organização do trabalho. Ferramentas de análise de decisão, tais como critérios múltiplos fornecem uma metodologia estruturada para identificar, avaliar e classificar as opções de gestão alternativa pode fornecer outra abordagem promissora para lidar com a complexidade e as incertezas inerentes à nanotecnologia (LINKOV et al. 2008).

O NIOSH lista uma série de espaços em branco no tocante à segurança no local de trabalho. Nesse passo, estabeleceu um conjunto de objetivos estratégicos para serem desenvolvidos entre 2013 e 2016. Entre eles, destacam-se: 1. Aumentar a compreensão dos potenciais perigos e riscos à saúde de trabalhadores relacionados aos nanomateriais; 2. Expandir a compreensão dos achados iniciais de risco de nanomateriais; 3. Apoiar a criação de materiais de orientação para informar os trabalhadores, empregadores, profissionais de saúde, agências reguladoras e tomadores de decisão sobre os perigos, riscos e métodos de gestão de risco de nanomateriais; 4 . Apoiar estudos epidemiológicos e de exposição de trabalhadores; 5. Avaliar e promover a adesão nacional com orientação de gestão de riscos, especialmente na avaliação da exposição, tecnologia de controle, PPE (equivalente ao EPI - equipamento de proteção individual, no Brasil) e o estabelecimento de limites de exposição ocupacional.

\section{Programas e Parcerias de natureza voluntária}

Tais iniciativas são um componente essencial para a supervisão responsável da nanotecnologia, dadas as limitações da regulamentação tradicional para o futuro próximo (BALBUS, 2007). Manfred Lachs (1994), ex Juiz da Corte Internacional de Justiça de Haia, afirma que diante dos processos de desregulamentação e aparecimento de novas esferas de poder, há uma redução da imperatividade do Direito positivo, caracterizado por uma flexibilidade nunca antes vista, o chamado soft law. Segundo ele, novas técnicas de criação do direito apareceram e 
representam ferramentas importantes na época atual. Razão disso aduz ser preciso observar o fenômeno representado pelo aparecimento do que foi estabelecido chamar códigos de conduta, adotados, por exemplo, pela Organização para a Cooperação e Desenvolvimento Econômico (OCDE) e a Organização das Nações Unidas ou Conferência das Nações Unidas para o Comércio e Desenvolvimento (CNUCED).

Em relação à nanotecnologia aponta-se que a rápida velocidade de inovação e o pouco investimento estatal no estudo dos riscos, geraram um déficit de informação e competência (know-how técnico) e de capacidade de gerenciamento dos riscos, o que fez com que o Estado se distanciasse de assumir qualquer tipo de responsabilidade a respeito e estabelecesse novas relações de responsabilidade recíprocas entre sociedade, Estado e empresa. Levi-Four et al. (2007) destaca também que o comando e a regulamentação de controle são tradicionalmente utilizados pelo Estado quando os elaboradores do sistema regulamentar "conhecem e definem os problemas e as soluções com antecedência, e projetam as regras que imponham respostas adequadas". A limitação parece ser amplamente reconhecida por governos e órgãos reguladores em âmbito mundial, e é sem dúvida uma razão significativa a respeito de porque muitos governos, em grande parte, resistiram à tentação de aprovar novas disposições legislativas para as áreas de particular preocupação, como as apresentadas pelas tecnologias emergentes, sejam estas representadas pela biotecnologia, engenharia genética ou nanotecnologia.

Há três tipos principais de iniciativas voluntárias para a nanotecnologia: 1) agências governamentais podem patrocinar uma iniciativa direta e convidar a participação das partes privadas; 2) empresas individuais ou grupos de empresas de negócios podem organizar para atingir um conjunto de metas ou normas sanitárias e ambientais especificados para melhorar as práticas e o desempenho da indústria; e 3) as empresas comerciais e as Organizações Não Governamentais podem criar parcerias para perseguir objetivos compartilhados. O tipo 1 é chamado de "normas públicas" voluntárias, que servem como orientação para melhores práticas científicas e empresariais, programas e guias governamentais voluntários. Os tipos 2 e 3 são chamados de "normas privadas" de autorregulação, guias de melhores práticas elaborados e aplicados pela e na própria empresa para o manuseio seguro de nanomateriais.

Um exemplo de programa voluntário criado pelo governo americano é o Programa de Manejo de Materiais em Nanoescala da Agência de Proteção Ambiental (do inglês, EPA's Nanoscale Materials Stewardship Program) (EPA, 2009), o qual incentivou as empresas a apresentarem voluntariamente dados sobre seus nanomateriais ou se engajar em uma parceria de gestão de risco mais aprofundada com a agência governamental. Além dessa iniciativa, aponta-se o Esquema de Notificação Voluntária de Nanomateriais Manufaturados do Departamento de Assuntos Rurais, Ambientais e Alimentos do Reino Unido (DEFRA, 2006); o Código de Conduta da União Europeia para a investigação responsável no domínio da nanociência e da nanotecnologia. Os destinatários dessas normas voluntárias são Estados-Membros, entidades empregadoras e financiadoras de pesquisa, os pesquisadores (incluindo laboratórios privados) e, mais genericamente, todos os indivíduos e vol.09, nº. 04, Rio de Janeiro, 2016. pp. 2450-2488 2467 
organizações da sociedade civil envolvidas na nanociência e nanotecnologia.

Um exemplo de programa da indústria é o NanoSafety Consortium for Carbon (Consórcio de Nanossegurança em Carbono), um consórcio de empresas produtoras de nanotubos de carbono e outros nanomateriais à base de carbono com o objetivo de defender uma regulação mais efetiva e abordagens inovadoras de gestão para seus produtos.

Um exemplo de programa de parceria é a Nano Risk Framework (2007) co-criação do Environmental Defense Fund. and DuPont, nos Estados Unidos, que proporciona um quadro detalhado para avaliar e gerir os riscos dos produtos da nanotecnologia; o NanoSAFE Framework, parceria entre governo e universidades americanas; o Responsible NanoCode, uma iniciativa conjunta da Real Sociedade, Insight Investment e da Associação das Indústrias em Nanotecnologia, mais recentemente da Rede de Transferência de Conhecimento em Nanotecnologia, do Reino Unido. Outro exemplo é o Guide de bonnes pratiques Nanomatériaux et HSE elaborado em conjunto pela Fédération Française pour les Sciences de la Chimie com a I'Union des Industries Chimiques.

Marchant et al. (2012b) aduzem que embora haja alguma sobreposição na cobertura e participação entre as iniciativas, elas parecem em grande parte ter prosseguido em paralelo e não como parte de um esforço coordenado. As finalidades e características de programas destas iniciativas variam consideravelmente. Algumas são criadas principalmente para tornar as informações disponíveis, enquanto outros buscam atingir um resultado ambiental específico ou para desenvolver e aplicar uma nova tecnologia ou produto.

Uma das vantagens de iniciativas voluntárias é a sua flexibilidade e capacidade de adaptação e a oportunidade que oferecem para experimentar diferentes abordagens antes de bloquear num regime regulamentar mais amplo ou novo (NanoRiskFramework). A lacuna das iniciativas voluntárias é a ausência do elemento de coerção legal (GUNNINGHAM, 2009). Maus atores podem evitar tomar medidas adequadas e até mesmo serem capazes de usar falsa observância com o programa voluntário para proteger sua irresponsabilidade (RAMACHANDRAN, 2011). Outro problema com as iniciativas voluntárias é que elas não incutem o mesmo nível de confiança pública como fazem os programas reguladores tradicionais do governo (MACOUBRIE, 2005). E ainda, ao longo do tempo (conforme os produtos e o processamento incorporando materiais em nanoescala tornem-se maduros e cada vez mais tangíveis), tanto leis vigentes não específicas, quanto programas voluntários, conforme apontam estudos, possuem impacto no fazer das empresas, muito pouco efetivo (MARCHANT et al. 2012b; CONTI et al. 2008; WEIL, 2012). Podem se tornar ainda menos úteis quando aplicados a processos e aplicações da nanotecnologia, tais como "plataformas integradas e adaptáveis de entrega de drogas e alimentos que melhoram o valor terapêutico, os quais irão certamente desafiar a aplicabilidade dos marcos regulatórios existentes" (HODGE et al. 2014), bem como programas voluntários, considerando-se a natureza desvinculativa, não obrigatória e sem instrumentos de responsabilização jurídicos. 
Conforme apontam Invernizzi et al. (2013), a indústria química, com muito maior influência sobre os governos, tem direcionado o lobby para arrefecer qualquer iniciativa de regulação. No caso dos Estados Unidos, isso tem sido documentado pelo Fundo de Defesa Ambiental (UITA, 2007). Nos fóruns internacionais preparatórios e durante as Conferências Internacionais sobre Gestão de Substâncias Químicas (ICCM), a indústria química e os governos que compartilham seu posicionamento têm bloqueado sistematicamente qualquer iniciativa de precaução e regulação (DENISON, 2010; ICCM, 2009; SAICM, 2012). Inclusive, a indústria tem se oposto às medidas mais brandas de regulação, tais como as etiquetas de produtos, como, por exemplo, a posição da Johnson \& Johnson. Entretanto, alguns setores empresariais têm se posicionado pelas normas voluntárias, tais como os códigos de conduta, sendo os mais conhecidos os da Dupont em parceria com a Organização não Governamental Environmental Defense, BASF, Bayer, Johnson \& Johnson e Unilever.

Outros setores empresariais têm interesse em regulamentações parciais. Assim, por exemplo, as associações de supermercados da Suíça têm se manifestado pelas etiquetas de produtos com nanotecnologia (SWISSINFO, 2008). A companhia de seguros Continental Western Insurance Group (CWG) retirou seus seguros das empresas que processam ou utilizam nanotubos de carbono (LEXIXNEXIS, 2008). Há alguns esforços para estabelecer guias internacionais para a regulação. Contudo, elas são voluntárias e primordialmente voltadas para facilitar a comercialização de produtos, embora contenham também especificações quanto a riscos ocupacionais e ambientais.

Especialmente na Europa e nos Estados Unidos, o atual cenário da governança dos riscos da inovação da nanotecnologia está se estruturando com base em normas desprovidas de caráter sancionatório, em pelo menos duas grandes categorias de soft law (as "normas públicas" voluntárias e as "normas privadas" de autorregulação: ex., standards, recomendações, códigos de conduta, compliance programs), como descrevemos acima. O efeito cumulativo desses esforços é que os quadros normativos e regulamentares em torno da nanotecnologia são cada vez mais vistos como de responsabilidade de corporações (organizações econômicas e, não governamentais) e de cientistas individuais.

Vale ressaltar que mesmo que exista um acordo geral sobre o valor das iniciativas voluntárias/privadas (de natureza soft law) como parte de uma estratégia global de governança da nanotecnologia, o estudo publicado pelo PEN (2010) destaca que as mesmas não podem resolver as escolhas políticas relacionadas com os encargos/ônus da prova, balanceamento de risco-benefício e níveis de risco aceitáveis, entre outros, que as instituições políticas legitimamente devem fazer.

Nessa perspectiva, essas e outras iniciativas, bem como o programa Responsible Care do Conselho de Química Americano (ACC), de caráter privado, concebidas pelo mundo econômico e organizações internacionais, podem e devem ser combinadas e complementadas às normas legais estabelecidas pelo Estado (especialmente "quando as normas legais são completamente inexistentes, estruturalmente nada ambiciosas ou vol.09, no. 04, Rio de Janeiro, 2016. pp. 2450-2488 
muito vagas"), ou seja, segundo propõe Winter (2013), tais programas voluntários podem fazer parte de um portfólio de ferramentas e estratégias políticas que permitam uma governança e fiscalização mais dinâmica, flexível e eficaz para a indústria, seus materiais e seus produtos, a fim de responder aos desafios políticos impostos pela rápida e complexa evolução da nanotecnologia.

O objetivo dessas iniciativas deve ser o de estabelecer um conjunto de princípios internacionalmente relevantes que delineiam melhores práticas pelas empresas envolvidas em todos os aspectos das tecnologias emergentes e suas aplicações, incluindo pesquisa, desenvolvimento, fabricação, distribuição e venda, envolvendo segurança ocupacional e ambiental, definição internacional de padronização de terminologias, normas de segurança em casos de exposições pertinentes ou na ausência de informações de exposição e risco da nanotecnologia.

\section{Harmonização Internacional}

A nanotecnologia pode ser a primeira tecnologia verdadeiramente internacional em seu início, com toda a economia industrial promovendo ativamente e tentando beneficiar-se do desenvolvimento desta nova tecnologia, ao mesmo tempo (MORADI, 2005). Como tal, abordagens harmonizadas internacionalmente para a gestão de riscos da nanotecnologia, dão oportunidades e vantagens potenciais (BREGGIN, 2009, FRAMINGNANO, 2010, MARCHANT, 2009). Iniciativas regulatórias transnacionais permanecem primordiais dado que os riscos da nanotecnologia, se e quando eles se manifestam, são susceptíveis de transcender as fronteiras nacionais. Muitas grandes empresas envolvidas com a nanotecnologia têm instalações ou mercados ao redor do mundo, e os programas transnacionais de gestão de risco tão consistentes e critérios de aprovação regulamentar seriam mais eficientes e eficazes (MARCHANT, 2009). As normas internacionalmente harmonizadas também podem evitar muitos dos conflitos comerciais e ineficiências que têm dificultado outros produtos, como os alimentos geneticamente modificados. Além disso, como as empresas tentam equilibrar segurança e custos, estes acordos internacionais são essenciais para evitar uma corrida para o fundo em que as empresas simplesmente transferem operações para países com normas mais permissivas. ${ }^{5}$

Embora seja provável para o futuro um quadro regulamentar transnacional formal (BREGGIN, 2009), há uma série de iniciativas de harmonização internacional em curso para a gestão de riscos da nanotecnologia. Por exemplo, as organizações elaboradoras de padrãos consensuais internacionais, como a Organização Internacional de Padronização (ISO) que montou um comitê específico (ISO/TC/229-2008) para desenvolver padrões para a nanotecnologia, tais como termos e processos comuns que estabeleçam parâmetros para a indústria e ajudem no

\footnotetext{
${ }^{5}$ Mas Marchant (2009) reconhece que os esforços de harmonização internacional também têm algumas desvantagens, incluindo o enorme dispêndio de tempo e de recursos que seriam necessários para alcançar a harmonização e a injustiça potencial e ineficiências de tentar forçar países com diferentes perspectivas políticas, econômicas e sociais no mesmo quadro regulamentar. vol.09, nº. 04, Rio de Janeiro, 2016.pp. 2450-2488 2470
} 
desenvolvimento posterior da regulação; a Sociedade Americana para Testes de Materiais (ASTM International, E2456-06 e E2535-07), a Instituição Britânia de Normalizações (BSI, 2007a; 2007b), todas com comitês ativos para desenvolvimento de padrões internacionais, incluindo as normas para o meio ambiente, saúde e gestão de riscos de segurança da nanotecnologia.

Diálogo transnacional e fóruns de intercâmbio de informações, tal como a Organização para a Cooperação Econômica e Desenvolvimento (OCED) e o Grupo de Trabalho sobre Nanotecnologia, é outra iniciativa transnacional importante para facilitar a gestão de riscos harmonizada da nanotecnologia. A OECD criou um grupo de trabalho sobre materiais nanomanufaturados e outro sobre nanotecnologia para elaborar definições e guias para os países membros (ROLLAND et al.2013).

O Grupo de Trabalho lançou uma série de projetos com a participação dos órgãos reguladores dos países industrializados em todo o mundo, incluindo um programa coordenado de testes de nanomaterial, o desenvolvimento de princípios de gestão de risco comuns, e outras iniciativas de compartilhamento de informações. Vários códigos de conduta têm sido desenvolvidos para os nanomateriais, incluindo o Responsible NanoCode e o Código de Conduta da União Europeia para a investigação responsável no domínio da nanociência e da nanotecnologia do Reino Unido (BOCHON, 2011), que se destinam a fornecer um conjunto internacional de normas de gestão de risco para as entidades de manipulação com nanomateriais. Essas e outras iniciativas estão lançando as bases para uma abordagem de gerenciamento de risco internacionalmente harmonizada, não só para facilitar o desenvolvimento responsável da nanotecnologia, mas também está estabelecendo um precedente útil para abordagens globais harmonizadas de tecnologias futuras.

Invernizzi et al. (2013) também relatam que há, ainda, um espaço de negociação coletiva e multilateral, do qual participam governos, empresas, Organizações não governamentais, organismos internacionais e sindicatos. Trata-se da ICCM e seu órgão de ação, o SAICM (Abordagem Estratégica para a Gestão Internacional de Produtos Químicos) ${ }^{6}$ que se destaca no que diz respeito ao comércio internacional de produtos e substâncias que contenham nanomateriais. Embora não seja um tratado legalmente vinculante (soft law), constitui-se em compromisso político global, por parte dos governos e outras partes interessadas. Essa metodologia garante o manejo das substâncias químicas de forma segura, tanto para o trabalhador, quanto para o meio ambiente e a população, pois leva em conta o ciclo de vida do produto; reconhece os prejuízos à saúde e ao meio ambiente causados pela exposição às substâncias químicas e promete realizar uma ação efetiva para mudar a maneira como tais substâncias são produzidas e usadas visando minimizar prejuízos. O documento, criado em 2006, se caracteriza em sua elaboração, aplicação e monitoramento, pelo envolvimento e participação ampla do Estado,

\footnotetext{
${ }^{6}$ Marco político internacional resultante dos esforços para reforçar a cooperação internacional entre governos e outras partes interessadas (como empresas e organizações da sociedade civil) com relação à segurança química.
} 
organizações internacionais, ${ }^{7}$ da sociedade civil e das empresas, ${ }^{8}$ tanto a nível local, regional, nacional ou global.

Embora suas decisões não sejam de cumprimento obrigatório, em 2012 a ICCM-3 decidiu incluir os produtos nanomanufaturados no Plano Global de Ação do SAICM, o que significa que os países deverão implementar ações tendentes a desenvolver programas de monitoramento e segurança laboral, do consumidor e do ambiente e divulgar e melhorar a informação sobre todo o desenvolvimento de produtos e serviços contendo nanotecnologia.

Para Berger Filho et al. (2013), deve-se ampliar a participação ativa das instituições brasileiras nas discussões internacionais, no âmbito de organizações como o SAICM, além da ISO, em especial no Grupo de Trabalho ISO-TC 229. Os autores sugerem ainda, a necessidade de ser fomentada a criação e a manutenção de canais de cooperação com órgãos governamentais de países na América Latina e em outros continentes, com atenção às informações produzidas em instituições nas quais se percebe um avanço maior no debate e desenvolvimento de marcos regulatórios e estratégias de governança dos riscos oriundos da nanotecnologia, como é o caso das agências governamentais europeias, norte-americanas e da OCDE.

\section{COBERTURA DE SEGURO E CONSÓRCIOS}

O seguro é outra ferramenta potencial e um desafio para a gestão do risco de nanotecnologia (MEDER, 2010). ${ }^{9}$ Dada a falta de uma regulação eficaz e normas de gestão de risco estabelecidos para a nanotecnologia, as seguradoras desempenham um papel potencialmente importante na promoção de práticas seguras e de gestão de risco para seus clientes. Ao mesmo tempo, como o número de produtos da nanotecnologia chegando ao mercado continua a subir, esta apresenta riscos potenciais altamente incertos (particularmente em longo prazo); além disso, os potenciais riscos e incertezas para as seguradoras se tornam cada vez mais problemáticos (CRO Forum, 2010), pois a nanotecnologia apresenta riscos desconhecidos, enquanto a indústria de seguros é baseada na

\footnotetext{
7 Participam da SAICM as seguintes organizações internacionais: Programa das Nações Unidas para o Meio Ambiente (PNUMA), Organização das Nações Unidas para a Agricultura e a Alimentação (FAO), Organização Internacional do Trabalho (OIT), Organização Mundial de Saúde (OMS), Organização de Cooperação e Desenvolvimento Econômico (OCDE), Organização das Nações Unidas para o Desenvolvimento Industrial (ONUDI), Instituto das Nações Unidas para Formação e Pesquisa (UNITAR), Fundo para o Meio Ambiente Mundial, Programa das Nações Unidas para o Desenvolvimento (PNUD), Banco Mundial, Programa Interorganizações para a Gestão Segurança de Produtos Químicos (IOMC), Foro Intergovernamental sobre Segurança Química (IFCS).

${ }^{8}$ Entende-se que os principais interessados na abordagem estratégica são os governos, as organizaçoes regionais de integração econômica, organizações intergovernamentais, organizações não governamentais e pessoas envolvidas na gestão dos produtos químicos, durante seu ciclo de vida, a representação de todos os setores relevantes, incluindo a agricultura, o meio ambiente, a saúde, a indústria, as atividades econômicas relevantes, a cooperação para o desenvolvimento dos trabalhadores e da comunidade cientifica, mas não estão limitados a eles. Interessados individuais incluem: os consumidores, trituradores, empregadores, agricultores, produtores, reguladores, pesquisadores, fornecedores, transportadores e trabalhadores.

9 Tecnicamente, o seguro é um método de transferência de risco, em vez de gestão de riscos. No entanto, através da imposição de requisitos e recomendações para o gerenciamento de riscos como condição para aceitar a transferência do risco, seguradoras atuam como gestores de fato do risco.
} 
avaliação, gestão e alocação de risco. As seguradoras temem que os riscos desconhecidos da tecnologia poderão resultar em riscos catastróficos de grandes proporções semelhantes aos incorridos pelas seguradoras na crise do amianto (FINK, 2010, CRO Forum, 2010).

As companhias de seguros já podem estar cobrindo atividades com nanotecnologia, quer saibam disso ou não. Por exemplo, apólices de seguro de responsabilidade comercial geral protegem as empresas de responsabilidades comuns, incluindo lesões corporais. Estas e outras políticas gerais já podem incluir ferimentos causados por nanotecnologia a menos que tais produtos estejam especificamente excluídos pela política. Isto levou pelo menos uma seguradora implementar uma exclusão para a nanotecnologia, embora a aplicação e o alcance de tal exclusão seja ainda indeterminada (MONICAJR, 2008). Como escrito, as referências amplas e um tanto ambíguas da exclusão à nanotecnologia corre o risco de inibir a inovação futura por negar cobertura e, portanto, desencorajar o uso da tecnologia (WAXMAN et al. 2009).

Uma abordagem proposta para o seguro de atividades contendo nanotecnologia é uma solução públicoprivada, como a criação de um consórcio de seguros, que exigiria a participação obrigatória de todas as empresas fabricantes da tecnologia (RAKHLIN, 2008). No entanto, esta abordagem tem muitas limitações e problemas, tais como potencialmente colocando as empresas dos Estados Unidos em desvantagem competitiva em relação aos seus concorrentes internacionais, que não podem ser obrigados a incorrer em despesas semelhantes. Outra opção seria a de produtos de seguro com base no grau dos riscos conhecidos ou percebidos associados com diferentes aplicações da nanotecnologia, combinado com os requisitos e incentivos de gestão de risco ativos e bem informadas. A organização Lexington Insurance Company tem percorrido este caminho, introduzindo o primeiro seguro específico-nano, LexNanoShield (MONICA JR. 2010). Este produto possui uma variedade de serviços de gestão de riscos projetados para empresas que utilizam nanotecnologia e ajuda seus clientes a avaliar e gerenciar os riscos. Outras companhias de seguros estão desenvolvendo as suas próprias políticas especializadas para a nanotecnologia, bem como ferramentas de gestão de risco para ajudar a entender e minimizar os riscos de produtos e processos nanotecnológicos (CRO Forum, 2010, MEDER, 2010).

\section{O Princípio da Precaução}

Conforme analisamos alhures, nenhuma discussão sobre a gestão de riscos da nanotecnologia seria completa sem menção da precaução e o princípio da precaução. A precaução prudente é um componente adequado e necessário de supervisão de uma tecnologia como a nanotecnologia com importantes benefícios, mas também riscos altamente incertos (MURASHOV et al. 2009). Como um painel dos principais especialistas em nanotecnologia concluiu, "neste momento, não é possível implementar uma abordagem regulamentar robusta e confiável com base científica para nanoprodutos. Nesta situação, é importante garantir que as medidas de 
precaução adequadas orientem a avaliação científica dos riscos e da seleção de padrões de segurança" (COUNCIL OF CANADIAN ACADEMIES, 2008).

Os benefícios importantes da nanotecnologia ficariam comprometidos se os riscos desconhecidos ou incertos resultassem em danos graves. Os riscos não apenas causariam prejuízos para as vítimas, também seria para as empresas que fabricam e vendem esses produtos, as seguradoras que estão subscrevendo as empresas e os reguladores (governos) com responsabilidade de supervisão desses produtos. Assim, é do interesse de todos aplicar um grau razoável de precaução na tentativa de minimizar os riscos de danos a partir da tecnologia e, ao mesmo tempo, procurar minimizar quaisquer atrasos ou negação dos benefícios da mesma tecnologia.

Nos últimos anos, a precaução foi implementada através da emergência do princípio da precaução. $\mathrm{Na}$ sua forma mais básica, sustenta que quando os riscos potenciais de uma tecnologia emergente são desconhecidos, a tecnologia deve ser restrita até que o proponente da tecnologia demonstre que a mesma é segura (EEB, 1999). Esta abordagem, em sua forma mais rigorosa (forte), muitas vezes leva a chamadas para deter tecnologias como a nanotecnologia. Por exemplo, o Erosion, Technology and Concentration Group (ETC GROUP) invocou o princípio da precaução para propor uma moratória sobre todo o desenvolvimento da nanotecnologia até a formulação de rigorosa regulação de âmbito internacional. O Centro Internacional de Avaliação Tecnológica (do inglês, International Center for Technology Assessment - ICTA), juntamente com mais de 40 outras organizações de defesa, também fez um apelo para uma moratória de fato sobre o desenvolvimento da nanotecnologia com base no princípio da precaução. Para o ICTA (2010) "o princípio da precaução deve ser aplicado à nanotecnologia porque a investigação científica em dia sugere que a exposição a pelo menos alguns nanomateriais, nanodispositivos, ou os produtos de nanobiotecnologia é susceptível de resultar em sérios danos à saúde humana e ao meio ambiente." A partir daí, muitos outros se juntaram a chamada para aplicar o princípio da precaução, que foi muitas vezes interpretado como exigindo uma moratória para a nanotecnologia (MILLER, 2007; SARGENT JR, 2010).

$\mathrm{Na}$ atual conjuntura em que não possuímos normas específicas para a nanotecnologia, o Estado (e demais operadores públicos e privados, em especial órgãos de proteção ambiental, sanitários e do consumidor, instituições de pesquisa e desenvolvimento científico/tecnológico, indústria e comércio, sociedade civil) "é obrigado a um agir activo e positivo na protecção do ambiente, qualquer que seja a forma jurídica dessa actuação (normativa, planeadora, executiva, judicial)". Esta proteção “vai muito para além da defesa contra simples perigos, antes exige um particular dever de cuidado perante os riscos típicos da sociedade de risco" (CANOTILHO, 2010). Nesse sentido, Berger Filho et al. (2012) apontam que medidas de precaução devem ser tomadas no sentido de impor:

1. O planejamento e uso da "melhor tecnologia disponível" durante todo ciclo de vida dos nanomateriais manufaturados para minimizar os riscos para o meio ambiente, trabalhadores e consumidores. 
2. O monitoramento constante dos riscos e do impacto das diferentes aplicações da nanotecnologia ao longo de seu ciclo de vida, à custa dos laboratórios e indústria desenvolvedores e produtores. Isso pode ser concretizado por meio da autorregulação (voluntária) ${ }^{10}$ ou da exigência legal (obrigatória) de estudos de avaliação científica sobre a segurança dos nanoprodutos/nanomateriais antes de serem colocados no mercado, e também depois de iniciada sua comercialização e consequentemente, maior manipulação pelos trabalhadores, utilização pelo consumidor e descarte de resíduos.

3. Atribuir a responsabilidade de produzir informações a quem desenvolve, fabrica, importa ou distribui produtos contendo nanotecnologia, como aquelas exigidas pela França quando da modificação de seu Code de l'environnement, regulamentado pelo Decreto (no 2012-232) de 17 de fevereiro de 2012, acrescentando capítulo específico para tratar da "Prevenção de riscos à saúde e ao ambiente decorrentes da exposição a substâncias no seu estado de nanopartículas".

Nesta perspectiva, Engelmann et al. (2014) entendem que os avanços tecnológicos existentes na sociedade contemporânea detêm um reflexo paradoxal: ao mesmo tempo em que acrescem qualidade de vida às pessoas, estes são capazes de gerar riscos de potenciais altamente nocivos à saúde e ao meio ambiente. "Para que as instâncias de comunicação (Direito, Economia e Política) possam reagir aos ruídos produzidos por uma nova forma social pós-industrial (produtora de riscos e indeterminações científicas), estas devem construir condições estruturais para tomadas de decisão em um contexto de risco", neste caso, a Constituição da República Federativa do Brasil, como fonte maior do Direito "servirá para explicitar a tensão entre o mundo dos valores e o mundo da regulação social, fazendo com que a sociedade integre no seu cotidiano normas, que não se resumem à solução de conflitos interindividuais ou grupais, mas que forneçam os parâmetros de uma sociedade, garantidora do bem comum, da segurança jurídica e da justiça” (BARRETTO, 2006).

Nessa perspectiva, o Direito enquanto regulador das relações sociais, deve articular o atual paradigma da humanidade, a sustentabilidade, que segundo Engelmann et al. (2014) anseia por uma nova sociedade capaz de perpetuar-se no tempo com condições dignas (sem a deterioração material do planeta), com a indicação/apontamento de maneiras de gestão dos riscos a fim de erradicar, ou no mínimo, minimizar as situações que também são insustentáveis: "a pobreza, a exclusão social, a injustiça e a opressão, bem como a dominação cultural e econômica". E a era nanotecnológica com suas promessas de alterar o "tecido" da sociedade para uma nova estrutura, tal sustentabilidade poderá ocorrer, desde que o desenvolvimento nessa escala, obedeça

\footnotetext{
${ }^{10}$ Através da ocorrência instrumentalizada por Guias de boas práticas, certificações, códigos de conduta desenvolvidos por instituições privadas como associações profissionais, organizações voltadas para a padronização técnica, institutos de pesquisa, corporações transnacionais ou organizações não governamentais, como: o ED-DuPont Nano Risk Framework, da empresa Dupont em parceria com Environmental Defense Fund, (ONG Norte Americana); Basf Code of Conduct Nanotechnology, da empresa alemã Basf; Guide de bonnes pratiques Nanomatériaux et HSE elaborado em conjunto pela Fédération Française pour les sciences de la Chimie com a l'Union des Industries Chimiques.
} 
a parâmetros que respeite os direitos fundamentais tutelados na Constituição Federal.

Significa dizer com MORIN (2011) "a consideração de toda essa complexidade, a partir dos efeitos inesperados ou perversos do ato, exige 'trabalhar pelo pensar bem', conforme a expressão de Pascal, ou seja, pensar de maneira complexa”. Eis que na sociedade de risco surgem conflitos de responsabilidade distributiva, isto é, acerca da distribuição, controle, prevenção e legitimação dos riscos decorrentes do avanço tecnológico e científico que produzem riscos invisíveis, imprevisíveis com os quais os instrumentos de controle falham e são incapazes de prevê-los, o que, para Engelmann et al. (2014), a partir da nanotecnologia a sociedade de risco recebe um ingrediente inusitado: "a produção de efeitos - negativos e positivos - em escala invisível e com as propriedades físico-químicas modificadas, um potencial de risco muito maior".

Ademais, como referido por Sarlet et al. (2014), no caso das pesquisas biomédicas envolvendo seres humanos, implicando não somente benefícios, mas riscos para a pessoa humana, o problema da proteção da dignidade, da liberdade, da vida e da integridade física e dos direitos de personalidade em geral ganha particular ênfase e desafia ampla e eficaz concretização dos deveres de proteção estatal, inclusive nas relações privadas, pois em boa parte dos casos (se não na maior parte) estão em causa pesquisas promovidas por instituições privadas (exemplo das pesquisas financiadas pela indústria farmacêutica e biotecnológica), o que, por sua vez, reflete no modo pelo qual acontece a articulação entre o Estado e a iniciativa privada, em especial no que diz respeito à regulação e ao controle pelo Estado da pesquisa, de seu conteúdo e de suas consequências.

Neste caso, os autores alertam que tanto o exercício da atividade de pesquisa propriamente dito quanto a sua divulgação e aplicação (incluindo a comercialização), impactam outros direitos fundamentais, sejam eles do próprio titular da liberdade de pesquisa sejam eles de terceiros, por essa razão, como acontece com os demais direitos fundamentais, a liberdade de pesquisa não é um direito absoluto: "Não apenas pode, como deve ser objeto de uma regulação de cunho protetivo e promocional da própria atividade de pesquisa e dos seus titulares, bem como deve ser submetida a intervenções restritivas, veiculadas preferencialmente por lei, com o intuito de preservar outros direitos fundamentais".

A relação entre o Direito e os avanços nanotecnológicos na América Latina é muito recente, mas absolutamente necessária. Nessa mesma direção vai o alerta de Delmas-Marty (2003, p. 138): “o desenvolvimento dos laços de pesquisa biomédica é o próprio exemplo de uma mutação que, por sua rapidez e amplitude, exigiria uma resposta jurídica mundial, sendo os riscos, então, na medida em que os ônus financeiros são altos, de deixar os argumentos econômicos e financeiros preponderarem sobre os direitos do homem e sobre as doenças".

Pode ser que com todos esses desafios, a tarefa de regulamentar a nanotecnologia pareça bastante difícil, mas "ao fazer nossas escolhas regulatórias, estamos fazendo escolhas sobre o tipo de sociedade que queremos e ter os valores que nos são caros" (BENNETT, 2008). Ignorar os problemas não vai fazê-los desaparecer, pois a vol.09, nº. 04, Rio de Janeiro, 2016. pp. 2450-2488 2476 
ciência médica e a tecnologia apresentam desafios de importância global (KIRBY, 2003).

\section{CONCLUSÃO}

Nesse momento de avanços tecnológicos, o desenvolvimento da nanotecnologia é considerado um novo capítulo na história mundial, pois possibilita aberturas para o progresso em diversas áreas do conhecimento. Nesse sentido, pode auxiliar tanto no avanço de técnicas já utilizadas quanto na produção de novos produtos, os quais atendem a necessidades pontuais do ser humano, principalmente na área da saúde, desde o combate ao câncer até a criação de produtos mais resistentes. Portanto, a situação hoje colocada pelas chamadas tecnologias emergentes e, nelas, a nanotecnologia, é um contexto caracterizado pela incerteza e ignorância que distinguem um estágio de precocidade tecnológica - e, portanto, econômico, social, político, jurídico e ético. Além disso, dada a inerente complexidade de interações entre as tecnologias e as sociedades, torna-se ainda mais difícil de prever com precisão as mudanças que essas tecnologias podem ter sobre o tecido social em que introduzida e desenvolvida.

Contudo, identificamos que, embora a ciência tenha como objetivo principal desenvolver o ser humano e de suas necessidades básicas, os rápidos avanços da tecnologia ocorridos no século XX e XXI acabaram fazendo com que centenas de inovações fossem inseridas no mercado, antes mesmo que concretos estudos referentes aos potenciais riscos fossem analisados, em especial, pela falta de conhecimento sobre os possíveis riscos que esta inovação poderá causar à saúde humana e ao meio ambiente, estando essa informação limitada aos altos níveis toxicológicos que ela apresenta, haja vista que os estudos realizados ainda não apresentam esse tópico.

Além disso, identificou-se que, na quase totalidade dos países produtores, inclusive no Brasil, há ausência de legislação estatal específica que contemple todas as especificidades de controle e gerenciamento dos riscos que a nanotecnologia exige durante toda a cadeia produtiva e ciclo de vida do desenvolvimento nanotecnológico. Tal fato soma-se à incerteza de que, embora existam normas jurídicas reflexas no âmbito internacional e nacional, como no caso dos tratados, das Diretivas do Parlamento Europeu e do Conselho, da Lei 12.305/2010, ${ }^{11}$ da Lei $11.105 / 2005^{12}$ e as diversas resoluções do Conselho Nacional do Meio Ambiente (CONAMA) no Brasil, concluímos que não existe um tratamento diferenciado para a problemática dos nanowastes (resíduos da nanotecnologia) e como já detectado por Engelmann (2010), não é claro se as normas jurídicas existentes são

\footnotetext{
${ }^{11}$ Quanto aos nanowastes, através do Projeto de Lei no. 6.741/13 busca-se adaptar a matéria por meio da Lei da Política Nacional de Resíduos Sólidos (Lei no. 12.305/2010). Nesse caso, conforme artigo 20 deste diploma legal, a priori, os rejeitos da nanotecnologia, quanto à periculosidade, podem ser classificados como: a) resíduos perigosos (aqueles que, em razão de suas características de inflamabilidade, corrosividade, reatividade, toxidade, patogenicidade [...] apresentam significativo risco à saúde pública ou à qualidade ambiental, de acordo com a lei, regulamento ou norma técnica ou b) resíduos não perigosos (aqueles não enquadrados na alínea "a").

${ }^{12} \mathrm{O}$ Brasil instituiu a Lei de Biossegurança (no. 11.105, de 24 de março de 2005), objetivando regulamentar os incisos II, IV e V do $\$ 1^{\circ}$ do art. 225 da Constituição Federal de 1988, e estabelecer normas de segurança e mecanismos de fiscalização de atividades que envolvessem organismos geneticamente modificados (OGMs) e seus derivados, além de criar o Conselho Nacional de Biossegurança (CNBS), o qual reestruturou a Comissão Técnica Nacional de Biossegurança (CTNBio).
} 
adaptáveis à proteção do meio ambiente e da saúde humana, diante da especificidade e pluralidade da nanotecnologia em pleno desenvolvimento e comercialização.

Diante das complexidades e contingências que se apresentam à sociedade, caso das tecnologias convergentes, em especial da nanotecnologia e sua arquitetura para o Século XXI: alterar o "tecido" da sociedade para uma nova estrutura, utilizando-se multidisciplinarmente de várias áreas do conhecimento - biologia, medicina, engenharias, química, fisica, e, com isso, causando impactos de grande monta, também nos diversos sistemas sociais: econômico, científico, político, jurídico, social, e para não repetir ações difíceis (ou a falta delas) sobre os rápidos avanços e também os inevitáveis impactos e desafios decorrentes da revolução industrial anterior (exemplo do amianto, do uso indiscriminado do DDT e outros), descreveram-se alguns princípios e indicadores para a supervisão da nanotecnologia, tornando-se imperioso que a ciência do Direito se preocupe com os diferentes aspectos dessa tecnologia, possibilitando a criação de instrumentos jurídicos com objetivo de efetivar medidas de gerenciamento preventivo do risco, baseado nos princípios da prevenção, da precaução, da responsabilização, da informação e da sustentabilidade, em perspectiva prospectiva para as presentes e futuras gerações de pessoas, incluindo a defesa do meio ambiente.

Além dos princípios e indicadores e, em razão da regulamentação governamental por si só, não ser suficiente para o futuro próximo para garantir o desenvolvimento seguro, descreveram-se algumas propostas estratégicas de gestão de riscos para a nanotecnologia, incluindo controles no local de trabalho, programas voluntários, seguros, além do princípio da precaução. Tais abordagens objetivam através da gestão de risco, maximizar os benefícios de uma tecnologia, produto ou atividade ao mesmo tempo, buscando identificar, avaliar e controlar os riscos associados à tecnologia, produto ou atividade. Neste caso, a gestão de riscos poderá ser feita em vários níveis, inclusive por agências reguladoras na definição de normas ambientais, de saúde e de segurança, por empresas na implementação de programas de manejo industrial de higiene e produtos e pelas seguradoras na formulação de políticas de cobertura e preços.

\section{STRATEGIC PROPOSALS FOR RISK MANAGEMENT FOR NANOTECHNOLOGY}

\section{Abstract}

Research on the use of nanoscale emerge as one of the most spectacular possibilities of science in the twenty-first century, with skills of building materials, devices and systems with atomic precision, able to act in a fundamentally different way compared to their respective material macro scale. Despite the spread of materials and equipment containing nanoparticles, the possible risks and impacts on public health and the environment have not been evaluated, added to the fact of absence, in almost all producing countries, including Brazil, specific legislation establishing management guidelines and monitoring of nanotechnology throughout their life cycle. For the bibliographic analysis, we describe some principles and indicators that should be adopted as supervisory measures and preventive management of risks of nanotechnological development, in order to ensure legal security to those vol.09, no. 04, Rio de Janeiro, 2016. pp. 2450-2488 
involved in the process and nanotechnology production, among which the approach precautionary and mandatory specific regulations. Also pointed out some strategic proposals for risk management, including controls in the workplace, volunteer programs and insurance. We conclude that the risk management of nanotechnology can be done at various levels, including government regulatory agencies in the definition of environmental, health and safety, companies in the implementation of industrial management programs and hygiene products and insurers in the formulation coverage and pricing policies.

Keywords: Nanotechnology and Law. Nanotechnological risk. Indicators for risk management.

\section{REFERENCIAS}

ABBOTT, K.W. Soft Law Oversight Mechanisms for Nanotechnology, Jurimetrics J., 2008, 52, 279.

ACTION GROUP ON EROSION, TECHNOLOGY AND CONCENTRATION: http://www.etcgroup.org/search.asp?theme=11, acessada em março 2015.

AGÊNCIA BRASILEIRA DE DESENVOLVIMENTO INDUSTRIAL. (ABDI). Nanotecnologias: subsídios para a problemática dos riscos e regulação. Brasília: ABDI, 2011.

Panorama Nanotecnologia. Série Cadernos da Indústria ABDI. Brasília, 2010. Disponível em: http://www.abdi.com.br/Estudo/Panorama\%20de\%20Nanotecnologia.pdf. Acessada em Maio de 2015.

AMERICAN SOCIETY FOR TESTING AND MATERIALS (ASTM INTERNATIONAL). Standard guide for handling unbound engineered nanoscale particles in occupational settings, 2007.

ANDRADE, L.R.B.; AMARAL, F.G.; WAISSMANN, W. Análise de propostas de gestão de riscos em ambientes com atividades envolvendo nanomateriais. Vigilância Sanitária em Debate, 2013, vol. 1, n. 4, 25-37.

ARAGÃO, A. Princípio da precaução: manual de instruções. Revista do Centro de Estudos Direito do Ordenamento, do Urbanismo e do Ambiente, Coimbra, n. 22, a. XI, 2008, 2, 9-57.

ARAGÃO, M.A.de S. O princípio do nível elevado de proteção e a renovação ecológica do direito ambiental e dos resíduos, Almedina, Coimbra, 2006.

BALAS, F. Reported Nanosafety Practices in Research Laboratories Worldwide, Nature Nanotechnology, 2010, 5,93 .

BALBUS, J.M. Protecting Workers and the Environment: An Environmental NGO's Perspective on Nanotechnology,J. Nanoparticle Res., 2007, 9, 15-16.

BARRETTO, V.A Leitura Ética da Constituição. 2006. Disponível em: http://www.egov.ufsc.br/portal/sites/default/files/anexos/15287-15288-1-PB.pdf, acessada em Agosto 2015.

BECK, U. World Risk Society. 2. ed. Londres: Polity Press, 1999.

BENNETT, B. Health Law's Kaleidoscope: Health Law Rights in a Global Age, 2008, 5-14.

BERGER FILHO, A.G., ENGELMANN, W. Reflexões sobre novos rumos para a regulação das nanotecnologias, vol.09, no. 04, Rio de Janeiro, 2016. pp. 2450-2488 
In Relações de consumo: tecnologia. [Org.] Agostinho Oli Koppe Pereira, Luiz Fernando Del Rio Horn. Caxias do Sul, RS: Educs, 2013.

Desenvolvimento das nanotecnologias, precaução e o direito ao meio ambiente ecologicamente equilibrado, In: Princípios do direito ambiental [recurso eletrônico]: atualidades/ Org. Clóvis Eduardo Malinverni da Silveira - Dados eletrônico - Caxias do Sul, RS: Educs, 2012.

BOCHON, A. Evaluation of the European Commission Recommendation for a Code of Conduct for Responsible Nanosciences and Nanotechnology Research, Nanotechnology L. \& Bus. 2011, 8, 117.

BOWMAN, D; HODGE, G. Governing Nanotechnology without Government, Sci. Pub. Pol'y, 2008, 35, 476, 479-84.

BREGGIN, L. Securing the Promise of Nanotechnologies: toward Transatlantic Regulatory Cooperation 15-83, 2009: Disponível em http://www.chathamhou se.org/sites/default/files/public/Research/Energy,\%20Environment\%20and\%20Development/r0909 _nanotechnologies.pdf.

BROWNSWORD, R. Rights, Regulation, and the Technological Revolution. Review by: Belinda Bennett, Journal of Law and Society, Vol. 35, n. 4 (Dec., 2008), 559-564.

BURLESON, D.J., DRIESSEN, M.D., PENN, R.L. On the characterization of environmental nanoparticles. J. Environ. Sci. Health Part A., 2004, 39, 2707-2753.

CANOTILHO, J.J.G. O Princípio da sustentabilidade como Princípio estruturante do Direito Constitucional. Tékhne, Revista de Estudos Politécnicos, 2010, n.13, 07-18. ISSN 1645-9911.

CARVAlHO, C.G.de. O que é Direito Ambiental. Dos Descaminhos da Casa à Harmonia da Nave. Florianópolis: Habitus, 2003.

CASTRO, C.R.S. Constituição Aberta e os Direitos Fundamentais. Ensaios sobre o constitucionalismo pósmoderno e comunitário. Rio de Janeiro: Forense, 2010.

CENTER FOR INTERNATIONAL ENVIRONMENTAL LAW. CIEL Plays Decisive Role in Global Chemicals Conference, 2009. Washington: CIEL: Disponível em: http://www.ciel.org/Chem/ICCM2_May09.html.

CLARK, K. A. Predictive Models for Nanotoxicology: Current Challenges and Future Opportunities, Reg. Toxicology Pharmacology, 201 1, 59, 361, 361.

COHEN, Y.; RALLO, R; LIU, R; LIU, H. In Silico Analysis of Nanomaterials Hazard and Risk, Accounts of Chemical Research, 2013, 46, 802.

CONTI JA, KILLPACK K, GERRITZEN G. Health and safety practices in the nanomaterials workplace: results from an international survey. Environ Sci Technol, 2008, 42, 3155-62.

COUNCIL OF CANADIAN ACADEMIES. Expert Panel on Nanotechnology. Small is Different: A Science Perspective on the Regulatory Challenges of the Nanoscale, 2008, 13.

CRO FORUM. Nanotechnology Crobriefing: emerging risks initiative-position paper 3, 2010: Disponível em http://www.nanowerk.com/nanotechnology/reports/reportpdf/report138.pdf. 
DELMAS-MARTY, M. Três Desafios para um Direito Mundial. Trad. Fauzi Hassan Choukr. Rio de Janeiro: Lúmen Júris, 2003.

DENISON, R. State-level nano regulation: Yes, indeed, the industry "should have seen it coming" - it caused it! 2010: Disponível em: http://blogs.edf.org/health/2010/09/10/state-level-nano-regulation-yes-indeed-theindustry-should-have-seen--it-coming-\%E2\%80\%93-it-caused-it/

DERANI, C. Direito Ambiental Econômico. São Paulo: Max Limonad, 1997.

ENGELMANN, W. Direitos bio-humano-éticos: os humanos buscando 'direitos' para proteger-se dos avanços e riscos (desconhecidos) das nanotecnologias. Anais do XIX Encontro Nacional do CONPEDI, realizado em Fortaleza - CE, nos dias 09, 10, 11 e 12 de Junho de 2010.

ENGELMANN, W.; HOHENDORFF, R.von. Das Nanopartículas aos Riscos em grande escala: os desafios e as possibilidades do emprego da precaução na implantação das nanotecnologias. In: Desafios socioambientais para a construção de um marco regulatório específico para a nanotecnologia no Brasil: anais do I Congresso Sul Brasileiro sobre Direito e Nanotecnologia. [ebook] / Orgs. Reginaldo Pereira, Silvana Winckler. São Leopoldo: Karywa, 2014: Disponível em https://editorakarywa.files.wordpress.com/2014/11/anais-do-i-congresso-sulbrasileiro-sobre-direito-e-nanotecnologia.pdf, acessada em janeiro 2015.

EUROPEAN COMMISSION. Agenda for NanoMedicine, 2005: ftp://ftp.cordis.europa.eu/pub/nanotechnology/docs/nanomedicine_visionpaper.pdf, acessada em janeiro 2015.

EUROPEAN ENVIRONMENTAL BUREAU. EEB. Protecting Public Health \& the Environment: implementing the precautionary principle 16-19, In: Carol Raffensperger \& Joel Tickner Eds. Position on the Precautionary Principle (Dec. 1999): Disponível em: http://www.eeb.org/publication/1999 /eeb_position_on_the_precautionar.html.

FERNÁNDEZ, M.C. Los problemas jurídicos planteados por las nuevas tecnicas de procreación humana. Barcelona: Bosch, 1995.

FERRONATO, R.F. Nanotecnologia, ambiente e direito: desafios para a sociedade na direção a um marco regulatório, (111 fls.) 2010. Tese (Mestrado em Direito) Universidade Caxias do Sul, Caxias do Sul (RS).

FINK, A. Insurance Coverage for Nanotechnology Risks Could Be a Big Deal, Martindale, 2010: http://www.martindale.com/insurance-law/article_1140684.htm.

FUKUYAMA, F. Nosso Futuro pós-humano: consequências da revolução da biotecnologia. Rio de Janeiro, 2003.

GILBERT, N. Nanoparticle Safety in doubt. Nature, 2009, 460, 937: doi:10.1038/460937a.

GRIMALD, D. C.; MORÁN, G. A. G.; MEJÍA, Ó. M.; RUIZ, A.; CARDONA, A. G.; TORRADO, C. A. C.; MEJÍA, M. V. Limits between molecular biology and nanotechnology: Impact on medicine. Iatreia, 2007, 20, 297.

GRIMM, D. Constituição e Política. Trad. Geraldo de Carvalho. Coordenação e supervisão Luiz Moreira. Belo Horizonte: Del Rey, 2006. 
GUNNINGHAM, N. Environmental Law, Regulation and Governance: Shifting Architectures, J. Envtl. L., 2009, $21,179$.

HANKIN, S. M. CABALLERO, N.E.D. Regulating nanotechnology in Brazil and the European Union. Ministério da Ciência, Tecnologia e Inovação. 2014: http://sectordialogues.org/sites/default/files/acoes/documentos/dialogos_setoriais_nanotecnologia_portugu es.pdf. Acessada em Agosto 2015.

HELLAND, A. Risk Assessment of Engineered Nanomaterials: A Survey of Industrial Approaches, Envtl. Sci. Tech., 2008, 42, 640.

HELLMAN, G. Employee Exposure to Nanomaterials Has Never Led to OSHA Citation, Official Says, Daily Env't Rep. (BNA), nº. 96, May, 2011.

HODGE, G.A.; MAYNARD, A.D.; BOWMAN, D.M. Nanotechnology: Rhetoric, risk and regulation, Science and Public Policy, 2014, 41, 1: doi: 10.1093/scipol/sct029.

INTERNATIONAL CENTER FOR TECHNOLOGY ASSESSMENT. (ICTA). Principles for the Oversight of Nanotechnologies and Nanomaterials: Disponível em http://www.state.gov/documents/organization/137963.pdf; ETC Group, http://www.etcgroup.org/upload/publication/pdf_file2/principles-for-the-oversight-of-nanotechnologies-andnanomaterials.pdf.

INTERNATIONAL CONFERENCE ON COMPOSITE MATERIALS. (ICCM). 2009. Disponível em http://iccm-central.org/Proceedings/ICCM17proceedings/Welcome.pdf, acessado em Março 2016.

INTERNATIONAL LABOUR ORGANIZATION. Emerging risks and new patterns of prevention in a changing world of 2010: http://www.ilo.org/public/portugue/region/eurpro/lisbon/pdf/28abril_10_en.pdf.

INTERNATIONAL ORGANIZATION FOR STANDARDIZATION. ISO/TC 229, 2008. Nanotechnologies - Health and Safety practices in occupational settings relevant to nanotechnologies.

INVERNIZZI, N; FOLADORI, G. Posições de Sindicatos e ONGs sobre os riscos e a regulação da nanotecnologia. Vigilância Sanitária em Debate, 2013, 1, 72-84.

JESUS, K.R.E., CASTRO, V.L.S.S., ASSIS, O.B.G. Análise Integrada dos Critérios de Segurança Ambiental dos nano produtos, Embrapa Gado de Leite, Juiz de Fora/MG, 01 a 05 de Setembro, 2014: disponível em http://www.alice.cnptia.embrapa.br/alice/bitstream/doc/1007370/1/2014AA49.pdf, acessada em Julho 2015.

KIRBY, M. Genomics and Democracy: A Global Challenge, U.W. Austl. L. Rev., 2003, 31, 1.

LACHS, M. O Direito Internacional no alvorecer do Século XXI. Estud. Av. [online]. 1994, 8, 47-118. ISSN 1806-9592.

LANONE, S.; BOCZKOWSKI, J. Biomedical applications and potential health risks of nanomaterials: molecular mechanisms. Current Molecular Medicine, 2006, v.6, n. 6, p.651-663. PMid:17022735. http://dx.doi.org/10.2174/156652406778195026. 
LEVI-FOUR, L.; COMANESHTER, H. The Risks of Regulation and the Regulation of Risks: The Governance of Nanotechnology. In New Global Regulatory Frontiers in Regulation: the Age of Nanotechnology, 2007, 149, 155 (Hodge, G.; Bowman, D.; Ludlow, K., Eds.).

LEXISNEXIS LEGAL NEWSROOM INSURANCE LAW. Nanotechnology Exclusion Implemented, 2008. Disponível em http://www.lexisnexis.com/legalnewsroom/insurance/b/insurance-lawblog/archive/2008/11/07/nanotechnology-exclusion-implemented.aspx 7

LICO JÚNIOR, R. de P. Nanotecnologia Análise Sócio-Científica. 2014. Disponível em http:/ /licoreis.com/wpcontent/uploads/2014/12/Unesp-Semin\%C3\%Al rio-Apresenta\%C3\%A7\%C3\%A3o-Nanotecnologiacompleto-01.pdf

LIMA NETO, F.V. Responsabilidade Civil das empresas de engenharia genética. Leme-SP. Ed. de Direito, 1997.

LINKOV, I.; SATTERSTROM, F.K. Nanomaterial Risk Assessment And Risk Management: Review of Regulatory. Nato Science for Peace and Security Series C: Environmental Security, 2009, 129-157.

LINKOV, I; SATTERSTROM, F.K. Nanomaterial Risk Assessment and Risk Management, in Real-Time and Deliberative Decision Making, 2008, 129, 149.

MACOUBRIE, J. Project on Emerging Nanotechnologies, informed public perception of nanotechnology and trust in government 1-2, 2005 .

MARCHANT, G.E, ATKINSON, B, BANKO, D, BROMLEY, J, CSEKE, E, FELDSTEIN, E, GARCIA, D, GRANT, J.M, HUBACH, C, SILVA, M, SWINFORD, R.L, WILLMAN, S. Big issues for small stuff: nanotechnology regulation and risk management. Jurimetrics Journal of Law, Science and Technology, Spring, 2012,243 .

MARCHANT, G.E. International Harmonization of Regulation of Nanomedicine, Stud. Ethics, L. \& Tech., 2009, $3,1,2$.

MAYNARD, A. Nanotechnology and occupational health: <http://epa.gov/ncer/nano/lectures/maynard_06_13_05_presentation.pdf.> Acessada em Agosto 2015. Palestra publicada no site da EPA, no hyperlink Nanotechnology: Lectures, 2005.

MAYNARD, A.D. Nanotechnology and Occupational Health, 2005: http://www.epa.gov/ncer/nanotechnology/lectures/maynard_06_13_05_presentation.pdf, acessada em Abril 2015.

MCCOMAS, K.A.; BESLEY, J.C. Fairness and nanotechnology concern, Risk Anal, 2011, 31, 1749. Doi: 10.1111/j.1539-6924.2011.01676.x.

MEDER, R.C. Risk Management and Nanotechnology: Insurance Concerns About Small Particles, Nanotechnology L. \& Bus. 2010, 7, 44, 44.

MILLER, G. Who's Afraid of the Precautionary Principle? Friends of the Earth - Emerging Tech Project, 2007: Disponível em http://emergingtech.foe.org.au/186;

MONICA JR, J.C. First Commercial Insurance Exclusion for Nanotechnology, Nanotechnology L. Rep. 2008. vol.09, nº. 04, Rio de Janeiro, 2016. pp. 2450-2488 2483 
Disponível em http://www.nanolawreport.com/2008/09/articles /nanoinsurance-issues-1/first-commercial insurance-exclusion-for-nanotechnology.

First Nano-Specific Insurance: Lexington Insurance Company Introduces LexNanoShield, Nanotechnology L. Rep, 2010: Disponível em http://www.nanolawreport.com/2010/03/articles/firstnanospecific-insurance-lexington-insurance -company-introduces-lexnanoshield.

MORADI, M. Global Developments in Nano-Enabled Drug Delivery Markets, Nanotech. L. \& Bus., 2005, 2, 139,141 .

MORIN, E.; O método 6 (Ética). Porto Alegre: Sulina, 2011.

MURASHOV, V; HOWARD, J. Essential Features for Proactive Risk Management, Nature Nanotechnology, $2009,4,467$.

NANO RISK FRAMEWORK. Disponível em http://www.nanoriskframework.com/frequently-askedquestions/.

NANOACTION. Principles for the oversight of nanotechnologies and nanomaterials, 2007. Disponível em: $<$ http://www.loka.org/Documents/nano_Principles_for_the_Oversight_of_Nanotechnologies_and_\%20N anomaterials_final.pdf>Acessada em 27 julho 2015.

NANOSAFETY CONSORTIUM FOR CARBON. Disponível em http://www.nanosafetyconsortium.com /\%5C/objectives.html

PELLIN, D.R; Engelmann, W. A nanotecnologia e a exploração das riquezas nacionais a partir da contribuição da análise econômica. Revista Quaestio Iuris, 2016, vol. 9, n. 01, Rio de Janeiro, 460-484 DOI: $10.12957 /$ rqi.2016.18887.

PINSON, R.D. Is nanotechnology prohibited by the Biological and Chemical Weapons Convention? Berkeley Journal of International Law, 2004, v. 22.

PORTER, M.E.; LINDE, C.van der. Verde e competitivo: acabando com o impasse. In: Porter, M.E. Competição. 9. ed. Rio de Janeiro: Campus, 1999.

PRESIDENT'S COUNCIL OF ADVISORS OF SCIENCE AND TECHNOLOGY. (PCAST). Report to the President and Congress on the Third Assessment of the National Nanotechnology Initiative. Washington, DC, 2010: The White House: Executive Office of the President: disponível em http://www.whitehouse.gov/sites/default/files/microsites/ostp/pcast-nano-report.pdf.

PRESIDENT'S COUNCIL OF ADVISORS OF SCIENCE AND TECHNOLOGY. (PCAST). Report to the President and Congress on the Fourth Assessment of the National Nanotechnology Initiative. Washington, DC, 2012: The White House: Executive Office of the President: disponível em http://nano.gov/sites/default/files/pub_resource/pcast_2012_nanotechnology_final.pdf

PRESIDENT'S COUNCIL OF ADVISORS OF SCIENCE AND TECHNOLOGY. (PCAST). Report to the President and Congress on the Fifth Assessment of the National Nanotechnology Initiative. Washington, DC, 2014: The White House: Executive Office of the President: https://www.whitehouse.gov/sites/default/files/microsites/ostp/PCAST/pcast_fifth_nni_review_oct2014_f inal.pdf, acessada em 17 julho 2015. 
PRESIDENT'S COUNCIL OF ADVISORS OF SCIENCE AND TECHNOLOGY. (PCAST). The National Nanotechnology Initiative at Five Years: Assessment and Recommendations of the National Nanotechnology Advisory Panel 35, 2005: Disponível em http://www.whitehouse.gov/sites /default/files/microsites/ostp/pcastnni-five-years.pdf.

PROJECT ON EMERGING NANOTECHNOLOGIES. Nanotechnology Consumer Products Inventory. 2013: http://www.nanotechproject.org/cpi.Acessada em Abril 2015.

PROJECT ON EMERGING NANOTECHNOLOGIES. Voluntary Initiatives, Regulation, and Nanotechnology Oversight - Charting a Path, 2010: http://www.nanotechproject.org/process/assets/files/8347/pen-19.pdf, acessada em Abril 2015.

QUINA, F.; Nanotecnologia e o Meio Ambiente: Perspectivas e Riscos, Quím. Nova. 2004, 27, 1028.

RAKHLIN, M. Regulating Nanotechnology: A Private-Public Insurance Solution, Duke L. \& Tech. Rev., 15-16, 2008: Disponível em: http://www.law.duke.edu/journals/dltr/articles/2008 DLTR0002.html.

RAMACHANDRAN, G. Recommendations for Oversight of Nanobiotechnology: Dynamic Oversight for Complex and Convergent Technology, J. Nanoparticle Res., 201 1, 13, 1348-50.

REJESKI, D.; LEKAS, D. Nanotechnology field observations: scouting the new industrial West, Journal of Cleaner Production, 2008, 16, 1014.

RESPONSIBLE NANO-CODE. Nanotechnology Andustries http://www.nanotechia.org/content/activities2/responsible-nano-code.

RICCARDI, C.dos S., GASTALDI, A.C. Nanoregulação: avaliação dos cenários internacional e brasileiro. R. Laborativa, 2013, v. 2, n. 2, p. 135-162. http://ojs.unesp.br/index. php/rlaborativa.

ROCHA, J.C.de C. Direito Ambiental e Transgênicos: princípios fundamentais da biossegurança. Belo Horizonte, Del Rey, 2008.

ROCO, M., REEN, O. Nanotechnology Risk Governance. 2012: http://irgc.org/wpcontent/uploads/2012/04/Chapter13_Nanotechnology__final.pdf. Acessada em abril 2015.

ROCO, M.C.; MIRKIN, C.A.; HERSAM, M.C. Nanotechnology Research Directions for Societal Needs in 2020 Retrospective and Outlook-NSF. WTEC report, September, 2010: http://www.wtec.org/Nano_Research_Directions_to_2020.pdf.Acessada em Abril 2015.

ROLLAND, S. Schools S. Transboundary Regulation in the Case of Nanotechnologies: A Theoretical Framing. Nanotech L \& Bus. 2013, 9, 318-29.

SARGENT JR, J.F. Nanotechnology and Environmental, Health, and Safety: issues for consideration. Cong. Research Serv., 2010, RL 34614.

The National Nanotechnology Initiative: Overview, Reauthorization, and Appropriations Issues. Congressional Research Service. (CRS) Report for Congress - Prepared for Members and Committees of Congress, August 9, 2013. 
SARLET, I. W.; PETTERLE, S. R.; Liberdade de pesquisa como direito humano e fundamental e seus limites: a pesquisa com seres humanos e os parâmetros protetivos estabelecidos pelo Direito Internacional e sua recepção no Brasil, Chapecó, v. 15, n. 1, p. 13-38, jan. /jun. 2014.

SCHULZ, P. Nanotecnologia, uma história um pouco diferente. Ciência Hoje, 2013, 308, vol. 52.

SCIENTIFIC COMMITTEE ON EMERGING AND NEWLY IDENTIFIED HEALTH RISKS. (SCENIHR). The Appropriateness of the Risk Assessment Methodology in Accordance with the Technical Guidance Documents for New and Existing Substances for Assessing the Risks of Nanomaterials, 2007: http://ec.europa.eu/health/ph risk/committees/04 scenihr/docs/scenihro 004c.pdf).

SILVA, M.B.da. Nanotecnologia: considerações interdisciplinares sobre processos técnicos, sociais, éticos e de investigação. Impulso, Piracicaba, 2003, 14(35): 75-93.

SONG, Y., LI, X., DU, X. Exposure to nanoparticles is related to pleural effusion, pulmonary fubrosus and granuloma. European Respiratory Journal, 2009, 34, 559-567.

STOKES, E. Regulating nanotechnologies: sizing up the options. Legal Studies 2009, 29 (2), pp. 281-304. http://dx.doi.org/10.1111/j.1748-121X.2009.00121.x

STRATEGIC APPROACH TO INTERNATIONAL CHEMICALS MANAGEMENT. (SAICM). 2012. Disponível em http://www.saicm.org/index.php?option=com_content\&view=article\&id=82:iccm3\&catid=90:iccm-3\&Itemid=473. Acessada em Março 2016.

STRECK, L.L. Decisionismo e discricionariedade judicial em termos pós-positivistas: o solipsismo hermenêutico e os obstáculos à concretização da Constituição no Brasil. O Direito e o Futuro, o Futuro e o Direito. Coimbra: Almedina, 2008.

SWISS REINSURANCE COMPANY. Nanotechnology: small matter, many unknowns. 2004. Zurich, Swiss Re: http://www.nanowerk.com/nanotechnology-report.php?reportid=93, acessada em Janeiro 2015.

SWISSINFO.CH. Researchers target nanotech risks, 2008. Disponível em http://www.swissinfo.ch/eng/researchers-target-nanotech-risks/6909164. Acesso em Março 2016.

THE FRAMINGNANO GOVERNANCE PLATFORM: a new integrated approach to the responsible development of nanotechnologies: Final Report 45, 2010: Disponível em http://www.framingnano.eu/images/stories/FinalConference/framingnano_complete_final_report.pdf.

TRAN, C.L. A Scoping Study to Identify Hazard Data Needs for Addressing the Risks Presented by Nanoparticles and Nanotubes, Institute of Occupational Medicine, December, 2005: http://randd.defra.gov.uk/Documentaspx?Document=CB01072_3060_FRP.doc. Acessada Abril 2015.

UNIÓN INTERNACIONAL DE TRABAJADORES DE LA ALIMENTACIÓN, AGRÍCOLAS, HOTELES, RESTAURANTES, TABACO Y AFINES. (UITA): http://www.iuf.org/w/?q=node/149. Acessada em Abril 2015.

UNITED KINGDOM DEPARTMENT FOR ENVIRONMENT, FOOD AND RURAL AFFAIRS (DEFRA), 2006. UK Voluntary Reporting Scheme for engineered nanoscale materials. London SW1P 3JR: Disponível em: http://www.defra.gov.uk/environment/nanotech/policy/pdf/vrs-nanoscale.pdf. 
UNITED KINGDOM ROYAL SOCIETY AND ROYAL ACADEMY OF ENGINEERING. Nanoscience and Nanotechnologies, July, 2005: http://www.nanotec.org.uk/report/Nano\%20 report\%202004\%20fin.pdf. Acessada em abril 2015.

UNITED STATES OCCUPATIONAL SAFETY \& HEALTH ADMINISTRATION (OSHA). European Agency for Safety and Health at Work Risk perception and risk communication with regard to nanomaterials in the workplace. 2012: Disponível em: <http://osha.europa.eu/en/publications/literature_reviews/riskperception-and-risk-communication-with-regard-to-nanomaterials-in-the-workplace $>$. Acesso em julho 2015.

UNITED STATES DEPARTMENT OF HEALTH AND HUMAN SERVICES. FOOD AND DRUG ADMINISTRATION. Nanotechnology A Report of the U.S. Food and Drug Administration Nanotechnology Task Force 16-19, 2007: Disponível em http://www.fda.gov/downloads/scienceresearch/specialtopics/nanotechnology/ucm1 10856.pdf. Acessada em Abril 2015.

UNITED STATES ENVIRONMENTAL PROTECTION AGENCY. Nanotechnology white paper, Washington DC, 2007: Disponível em: <http://epa.gov/ncer/nano/publications/whitepaper12022005.pdf>. Acessada em Agosto 2015.

Office of Chemical Safety and Pollution Prevention. Nanoscale Materials Stewardship Program: interim report 3, 2009: Disponível em http://www.epa.gov/oppt/nano/nmsp-interim-report-final.pdf.

Research on Nanomaterials. 2014. Disponível em https://www.epa.gov/chemical-research/researchnanomaterials. Acesso em março 2016.

UNITED STATES NATIONAL INSTITUTE FOR OCCUPATIONAL SAFETY AND HEALTH (NIOSH)._Current Intelligence Bulletin 65: Occupational Exposure to Carbon Nanotubes and Nanofibers, Abril, 2013: http://www.cdc.gov/niosh/docs/2013-145/, Acessada em Abril 2015.

UNITED STATES NATIONAL NANOTECHNOLOGY INITIATIVE. (NNI). Stakeholder Perspectives on Perception, Assessment, and Management of the Potential Risks of Nanotechnology - Report of the Workshop September,

2013:

http://www.nano.gov/sites/default/files/pub_resource/2013_nni_r3_workshop_report.pdf. Acessada em Abril 2015.

UNITED STATES NATIONAL RESEARCH COUNCIL (NRC). Research Progress on Environmental, Health, and Safety Aspects of Engineered Nanomaterials, 2014.

VIEGAS, T.E.de S.; ALMEIDA, R.de O. O Direito Ambiental Brasileiro em face dos Riscos e Incertezas da Nanotecnologia: uma Proposta de Reflexão Crítica. Artigo apresentado no III Simpósio Internacional de Propriedade e Meio Ambiente. São Luís. 2010. Disponível em https://pt.scribd.com/doc/30540848/O-DireitoAmbiental-Brasileiro-em-face-dos-riscos-e-incertezas-da-nanotecnologia-uma-proposta-de-reflexao-critica acessada em Janeiro 2015.

WAXMAN, J.M.; Lenz, E.D. The Coming Intersection of Nanotechnology and Synthetic Biology with Insurance, Life Sci. L. \& Industry Rep. (BNA), 2009, 3, 436.

WEIL, V. From the trenches: first-hand reports of how companies are managing nanotechnologies. Nanotech L \& Buss. 2012, 9, 253-66. 
WEISS, E.B. Intergenerational equity and rights of future generations. 1985. Disponível em http://biblio.juridicas.unam.mx/libros/4/1985/11.pdf. Acessada em maio 2015.

Un Mundo para Las Futuras Generaciones: Derecho Internacional, Patrimonio Común y Equidad Intergeneracional. Madrid: Ediciones Mindi-Prensa, 1999.

WIJNHOVEN. Nano-silver: a review of available data and knowledge gapsin human and environmental risk assessment. Nanotoxicology, 2009, 3, 109-138.

WINTER, G. Proporcionalidade "Eco-lógica": um princípio jurídico emergente para a natureza? Veredas do Direito, Belo Horizonte, 2013, v.10, n.20, p. 55-78, julho/dezembro.

YOKEL, R.A; MACPHAIL, R.C Engineered Nanomaterials: Exposures, Hazards, and Risk Prevention, J. Occupational Med. Toxicology, 2011,2.

Trabalho enviado em 23 de março de 2016.

Aceito em 18 de maio de 2016. 